\title{
Coping with Food Price Shocks in Afghanistan
}

\author{
Anna D'Souza and Dean Jolliffe
}

\subsection{Introduction}

Elevated global food prices have eroded the purchasing power of households throughout the developing world, many of whom spend the majority of their income on food. Given the potential implications for poverty, health and nutrition, and the outbreak of food riots, the short- and long-term impacts of high food prices are of much concern to governments, nongovernmental organizations, and aid agencies. During the 2007/2008 food price crisis, many households were pushed into or kept in poverty (World Bank \& International Monetary Fund 2012) and were forced to reduce the quantity and quality of food they consumed (International Fund for Agricultural Development 2008; Sanogo 2009). Field observations by the World Food Programme found that households also used nonfood coping strategies, such

as migrating, selling assets, taking children out of school, begging, and selling land (Ruel et al. 2010).

\footnotetext{
A. D'Souza $(\square)$

School of Public Affairs, Baruch College, City University of New York (CUNY), New York, NY, USA

e-mail: anna.dsouza@baruch.cuny.edu

D. Jolliffe

World Bank, Washington, DC, USA

e-mail: djolliffe@worldbank.org
} 
Much of the literature has emphasized the impact of food price increases on poverty rates. A smaller set of literature has examined the impact on nutritionrelated outcomes, such as undernourishment rates, calorie levels, and dietary diversity. Until now, little has been done to look at the implications of high food prices or food price increases on nonfood outcomes, such as nonfood expenditure or school enrollment. For the most vulnerable populations, living at or near subsistence levels, reducing the quality and quantity of food consumed, or cutting back on human capital investment (e.g., health and education expenditure) can have both immediate (e.g., wasting, increased illness) and long-lasting (e.g., stunting, intergenerational transmission of poverty) implications. More specifically, even short stints of poor nutrition can be detrimental to those with high nutritional needs like children, lactating and pregnant women, and the elderly (UNICEF 2009); and pulling children out of school could lead to long-term reductions in human capital accumulation since children are less likely to return to school after beginning to work (Guarcello et al. 2010).

In this chapter, we present evidence on household coping strategies from a nationally representative household survey collected in Afghanistan before and during the 2007/2008 food price crisis. These unique data come from the 2007/2008 National Risk and Vulnerability Assessment (NRVA) and cover over 20,000 households. During this period, due to a confluence of domestic (drought), regional (export bans), and international (food price crisis) factors, the price of wheat flour (the dietary staple) doubled. This represented a serious shock to Afghan households, who spend about $60 \%$ of their budget on food and who derive over half their calorie intake from wheat. We look at how Afghan households adjusted their expenditure patterns on food and nonfood items. We look at changes in various dimensions of food security, including calorie, dietary diversity, and nutrient intake. The last two indicators reflect the quality of food consumed and are related to "hidden hunger," a term that refers to micronutrient deficiencies which have serious implications for long-term human capital formation. And we look at the purchase of food on credit, the sale of productive assets, school enrollment, and migration.

We found strong evidence that the wheat flour price increases affected the well-being of Afghan households, who reduced both their food and nonfood expenditures. The reductions in the value of food consumed were reflected in reductions in the quantity and quality of food consumed, including reduced nutrient intake. Households reduced their nonfood expenditures across several categories, including health, clothing, grooming, communication, transportation, cigarettes and tobacco, and culture. And households purchased food on credit more frequently. We failed to find changes in educational expenditure or school enrollment, the sale of productive assets, or migration.

Since much of food security policy is concerned with those living at or below subsistence levels, it is important to allow for the possibility that the behavioral responses of vulnerable households differ from other households in ways that are 
policy relevant. Therefore, the food security analysis allows for differential price effects based on a household's food security level. We used the UQR estimator, proposed by Firpo et al. (2009b), to identify price effects for households located at specific points on the unconditional distributions (such as the 20th or 80th quantiles) of the food security indicators.

The evidence indicated that Afghan households, across the distribution, experienced a decline in the quantity and quality of food consumed as a result of the 2008 wheat flour price increases. We found disparities in the behavioral responses of households with respect to where the household lies on the unconditional distribution of the particular food security measure of interest. Households at the top of the calorie distribution, who can afford to cut back, experienced the largest declines in per capita daily caloric intake. The most vulnerable households-that is, those at the bottom of the calorie distribution - cannot afford to make substantial cuts to their caloric intake since they are close to or below the minimum daily energy requirements; accordingly, we found no statistically significant decline in their caloric intake.

Households at the bottom of the dietary diversity distribution—often very poor households - experienced very large declines in dietary diversity as a result of the wheat flour price increases (although even households at the top of the distribution experienced substantial declines). The bottom households are likely unable to make major cuts to caloric intake and thus must adjust the compositions of their diet to maintain energy levels. Such declines can exacerbate already high levels of malnutrition in Afghanistan.

This chapter is an extended version of the study by D'Souza and Jolliffe (2014). It provides an additional analysis of nonfood-based coping responses (i.e., adjustments to nonfood expenditures and behaviors). For completeness, we included the main results from D'Souza and Jolliffe (2014), which examined food-based household coping responses. Our work contributes to the understanding of how the people of Afghanistan were affected by and how they coped with staple food price shocks, providing a rare insight into the short-term coping mechanisms in a poor, conflict country. Such analysis is particularly crucial in conflict countries, which may be most susceptible to shocks but for which usually very little quantitative data are available.

In the next section, we provide details on Afghanistan during the study period. We then discuss the evidence regarding food-based and nonfood-based household coping responses. Thereafter, we describe the household data, the variables of interest, and our sample. We then present the empirical specifications and estimation techniques. We next discuss the results and conclude the chapter in the final section with a discussion of the major implications. 


\subsection{Background: Afghanistan Circa 2007/2008}

After decades of external and internal conflicts, ${ }^{1}$ along with prolonged droughts, the landlocked Afghanistan has one of the poorest, least well-nourished populations in the world. Despite strong growth, with real GDP growth averaging approximately $10.8 \%$ per year between 2003 and 2009, nearly $30 \%$ of the Afghan population did not meet the minimum daily food requirements of 2100 kilocalories per person in 2008 (MoE Islamic Republic of Afghanistan and the World Bank Economic Policy and Poverty Sector 2010). The IMF (2009) estimated that the gross domestic product (GDP) per capita in Afghanistan was \$350 in 2007 and \$457 in 2008 (current US $\$){ }^{2}$ Based on a broader set of development indicators used in the UNDP Human Development Index (e.g., health, education, living standards), Afghanistan ranked 181 out of 182 countries in 2008 (UNDP 2009). Approximately $60 \%$ of children under five suffered from chronic malnutrition (stunting), and $8 \%$ suffered from acute malnutrition (wasting) (Johnecheck and Holland 2007).

The Afghan economy is largely based on agriculture; major crops include wheat, rice, maize, barley, vegetables, fruits, and nuts. Approximately $70 \%$ of cultivated crop area is devoted to wheat, and about $15 \%$ is devoted to rice, barley, and maize (Chabot and Dorosh 2007). Wheat is both a major production crop and the main staple of the Afghan diet, contributing to $54 \%$ of the total caloric intake. Due to violence and large fluctuations in weather, however, wheat production is highly volatile, and the country is dependent on its trading partners to meet any shortfalls. Pakistan is Afghanistan's major supplier of wheat (mostly in the form of flour) due to close historical ties and a shared $1600 \mathrm{~km}$ border; Pakistan's share of the Afghan wheat and wheat flour import market is estimated to range from $59 \%$ (Chabot and Dorosh 2007) to $79 \%$ (Maletta 2004).

Levels of food insecurity vary greatly across the country, which is not surprising given Afghanistan's diverse terrain, climate, and agricultural zones. Seasonality plays an important role in food security in Afghanistan. Temperatures can vary dramatically across seasons, with hot summers and frigid winters, and the climate in the highlands varies with elevation. In many cases, severe winter conditions affect transportation, and in high mountainous areas, roads are often blocked throughout the winter due to heavy snow accumulation.

According to the World Food Programme, Afghanistan is among the world's most vulnerable countries in terms of absorbing food and fuel price shocks; such

\footnotetext{
${ }^{1}$ Afghanistan has a long history of conflict involving both intra- and interstate groups; for an overview of the conflict over the past 30 years, see Giustozzi and Ibrahimi (2012). In this chapter, we do not distinguish between different actors; rather we define conflict based on incidents of violence in which there are fatalities and/or casualties; more details are provided in the data section. ${ }^{2}$ In a country like Afghanistan though, where the drug economy is large, the official National Income Accounting data are likely to significantly understate GDP. UNODC (2008) estimates that in 2007 the farm gate value of opium cultivation was US\$1 billion, but this dropped to US\$730 million in 2008. The potential export value in 2007 of opium, morphine, and heroin at border prices in neighboring countries was $\$ 4$ billion (or, in per capita terms, about $\$ 160$ ).
} 
countries have consistently high levels of food insecurity, are heavily dependent on food and fuel imports, and have large populations of poor people who spend significant shares of their income on food (Sanogo 2009). Also, mountainous terrain and poor infrastructure, coupled with weak governance, insecurity, and corruption, have limited the government's ability to manage its food distribution and supply networks.

International prices of food commodities increased substantially in 2007 and rapidly in early 2008, peaking around May-July 2008. During this period, Afghanistan experienced several shocks that led to a disruption of its food supply network, causing prices to soar throughout the country. Due to drought and early snow melt, the 2008 wheat harvest of 1.5 million metric tons was the worst since 2000 (Persaud 2010). The price impact of the large shortfall in wheat production was magnified by export bans in Pakistan and rising international food prices. In February 2008, the Afghan government eliminated import tariffs on wheat and wheat flour (tariffs had been set at $2.5 \%$ ), but due to export bans in Pakistan, Iran, and Kazakhstan, the action brought about little downward effect on prices. Between fall 2007 and summer 2008, the prices of domestic wheat flour increased by over $100 \%$; Figure 21.1 displays retail wheat flour prices from 2002 to 2013 for four major urban centers collected by the FAO Global Information and Early Warning System (GIEWS).

In 2007/2008, total inflation was largely driven by the surge in food prices; Figure 21.2 depicts the consumer price indices (CPI) for food and nonfood items in urban areas from 2005 to $2011 .^{3}$ During the survey time frame

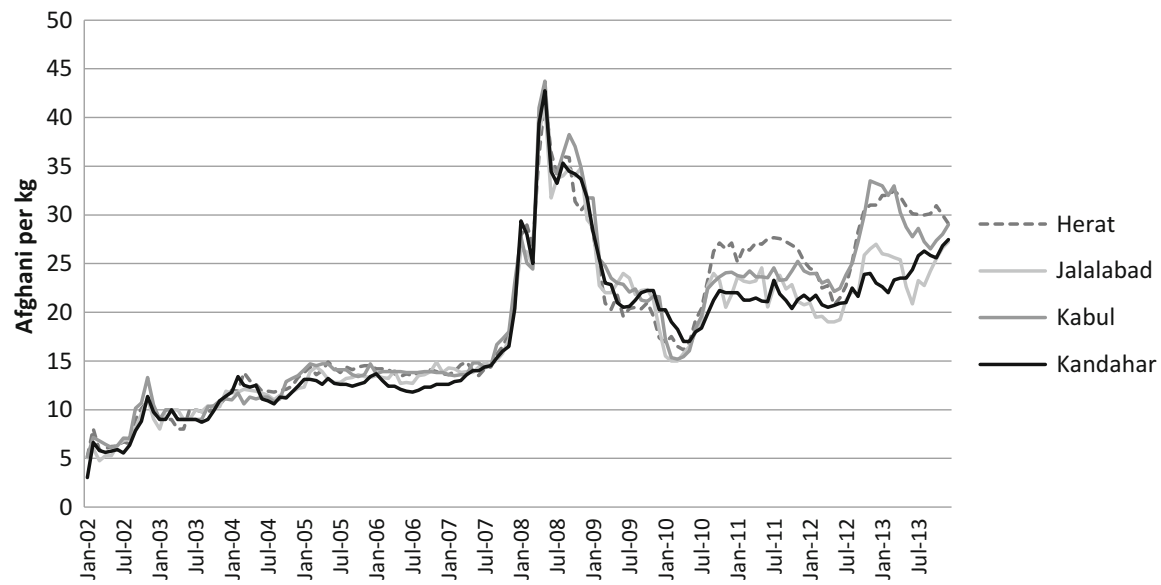

Fig. 21.1 Retail wheat flour prices, 2002-2013. Source: FAO GIEWS (2014)

\footnotetext{
${ }^{3}$ The indices were constructed by the Afghan Central Statistics Organization and are based on data from six urban areas.
} 


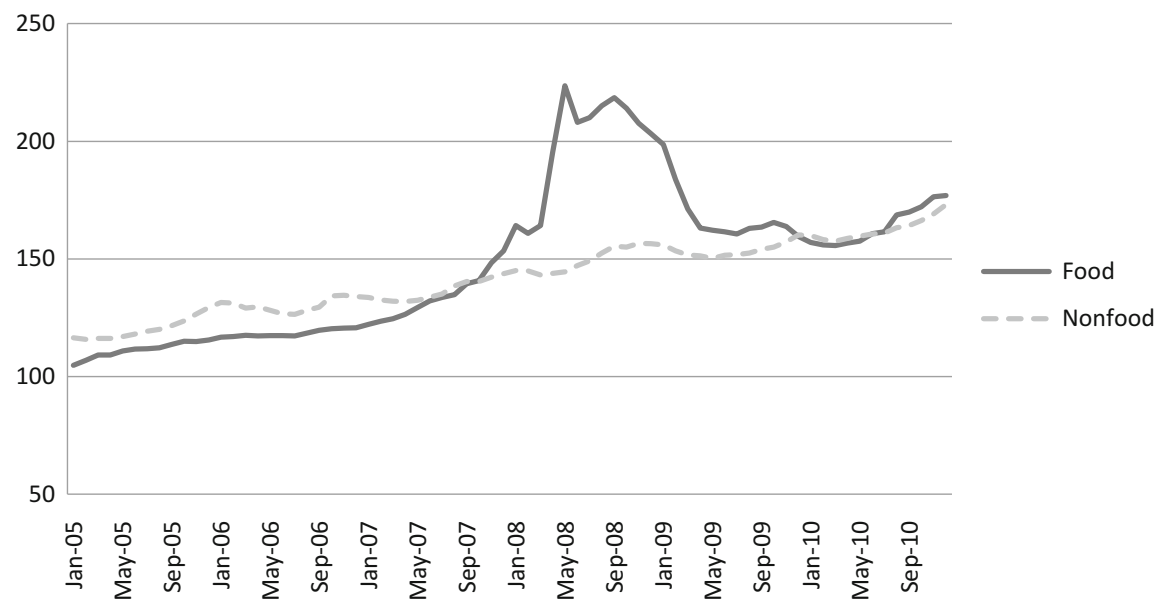

Fig. 21.2 Consumer price indices, 2005-2011

(August 2007-September 2008), the urban food CPI increased by nearly $60 \%$, while the nonfood CPI increased by only $10 \%$. Our calculations using price data collected in the NRVA also indicated a $60 \%$ increase in food prices in urban areas during this period, with an overall increase of $40 \%$ at the national level.

\subsection{Household Coping Strategies}

In response to price shocks or, more generally, negative shocks (e.g., income shocks, drought or natural disaster, death of main income earner), households employ a variety of coping strategies or responses. They may rely on family assistance, sell off assets, work more, borrow money, or-in the most desperate cases-reduce intake of food and nutrients. Such responses can be characterized as nonfood based or food based, and families can employ one or both of them (FAO 2008). Increases in food prices represent a decline in purchasing power for households. ${ }^{4}$ Nonfood-based coping strategies to deal with the reduced purchasing power include increasing time spent working for adults (and, in some cases, children); reducing expenditure on health, education, and other nonfood items; and changing household composition (e.g., migrating or sending children to live with relatives). In some instances, households remove children from school to save on school fees and to use the children as labor (at home, on the farm, or in the marketplace). Foodbased coping strategies include changing the type and quantity of food a household consumes and the people who consume the food in a household. Households may

\footnotetext{
${ }^{4}$ Below we discuss the potential income effect of increasing food prices for households that are net sellers of food.
} 
reduce the quantity (e.g., smaller meals, less frequently), quality, and diversity of foods consumed by moving toward cheaper food groups and cheaper foods within food groups.

Some of these strategies are reversible; for example, if prices decline, households can go back to purchasing higher-quality food. But other strategies are irreversible; for instance, after selling off productive assets, households may not be able to repurchase them even when food prices decline (Hadley et al. 2012). Furthermore, some of these responses can have long-term consequences for health and human capital development. For example, disinvesting in children (with respect to nutrition and/or schooling) can perpetuate the intergenerational transmission of poverty. Moreover, with over two billion people estimated to be suffering from mineral and vitamin deficiencies worldwide (Micronutrient Initiative and UNICEF 2009), further reductions in nutrition can have deleterious effects on households living below or near subsistence levels.

In this section, we discuss the current literature on food-based and nonfoodbased coping responses to high food prices. (See Ruel et al. (2010) for a more detailed review of the literature on the effects of economic crises on well-being, and see Compton et al. (2010) for a thorough review of the literature on the impacts of the 2007/2008 food price crisis.) Most recent studies on high food prices examined the implications for poverty rates rather than specific household coping responses. The studies often relied on data collected during periods of relatively stable prices and used the limited variation in prices to estimate price elasticities. Then these studies used simulation models to estimate the short-run effects of larger price shocks on measures of household welfare, primarily poverty rates, with many studies focusing on differences between outcomes for rural and urban areas. Examples of such studies include Wodon et al. (2008), who examined 12 African countries; Ivanic and Martin (2008), who examined nine low-income countries; Ul Haq et al. (2008), who examined Pakistan; Simler (2010), who examined Uganda; Robles and Torero (2010), who examined four Latin American countries; and De Hoyos and Medvedev (2011), who examined 73 low- and middle-income countries. In those studies, the magnitude of the impact of the crisis varied greatly among households and countries, and it depended on several factors, including the degree of price transmission, dependence on food imports, whether staple foods are traded internationally, whether the household is a net buyer or a net seller of food, and the household's reliance on staples. But the general finding was similar: national poverty rates increased, with urban areas on average suffering larger increases.

With this chapter, we are contributing to a smaller set of literature that examines the impact of recent high food prices on nutrition-related outcomes. Using data from eight developing countries, Anríquez et al. (2013) simulated the effects of staple food price increases on household undernourishment (defined as falling below daily calorie thresholds) for the average household, for urban and rural households, and by expenditure decile. The study showed that mean calorie levels generally declined with increasing staple food prices; however, countries varied in terms of the people who were the most negatively affected (e.g., poorest or middle quintiles, rural or urban populations) and in terms of the household-level determinants of the 
nutritional responses. Tiwari and Zaman (2010) also found that undernourishment rates increased across all major developing country regions assuming minimal levels of price transmission from international to domestic markets. Brinkman et al. (2010) looked at the impact of high food prices (and the global financial crisis) on food consumption, nutrition, and health outcomes for specific developing countries as well as several developing regions. Bibi et al. (2009) found that food poverty and undernourishment increased among children in Mali. In a study of rural Bangladesh, Torlesse et al. (2003) found that as rice prices fell, households reduced rice expenditure and increased non-rice food expenditure, thereby improving the quality of their diets. Klotz et al. (2008) provided a more nuanced view that households are likely to reduce the quality of food consumed before reducing the quantity of food consumed, and for this reason, individuals will experience micronutrient deficiencies before weight loss.

We are also contributing to the literature (including qualitative and quantitative studies) that examines nonfood-based coping responses (often in addition to foodbased ones) to increases in food prices. Compton et al. (2010) examined the literature and summarized the variety of nonfood-based coping strategies, which include reducing nonfood expenditure, pulling children out of school and increasing child labor, planting more food crops, increasing labor, increasing migration, selling nonproductive or productive assets, going into socially unacceptable livelihood activities (such as begging), and receiving increased aid from the government or nongovernmental organizations. Tandon and Landes (2014) found that in response to food price increases, Indian households decreased dietary diversity and delayed the purchases of health-related goods, clothing, and durable goods.

Sulaiman et al. (2009) showed that households in Bangladesh cut back on the number and quality of meals when food prices increased; they also found that households reduced expenditure on clothing, health, transportation, and cooking fuel. Looking at households in Somalia, Holleman and Moloney (2009) found reductions in nonfood expenditure (including money spent on medicine), increases in financial assistance (e.g., remittance, cash gifts, loans, credit purchases), and a drop in school enrollment. They also found that households switched to cheaper foods, for example, from imported rice to locally produced sorghum. And finally, Hadley et al. (2012) provided qualitative evidence from urban Ethiopia that increases in food prices can have an impact on important cultural practices, such as funerals, because households can no longer afford standard cultural practices at their socioeconomic level.

In studies based on simulation models, it is largely impossible to identify separately the extent to which the simulated estimates resulted from actual changes in household well-being or from modeling assumptions. Most studies have focused on the short run, assuming that (1) households and producers have no behavioral responses to the price increases, (2) there are no changes in input prices or wage rates, and (3) the proportional changes in consumer and producer prices are equivalent. In a recent contribution, Minot and Dewina (2013) demonstrated the sensitivity of poverty results to these standard assumptions. 
The need to simulate the welfare effects of a price increase is driven (partially) by a lack of comparable data before and after the price increase. Our study represents one of a handful of empirical analyses that have overcome the need to simulate welfare effects by using nationally representative household data collected prior to and during a significant price shock. Friedman et al. (2011) used nationally representative data from Pakistan to estimate reductions in calorie availability due to the 2008 food price spike and found an $8 \%$ reduction between 2006 and the first half of 2008. They also found that rural households with access to agricultural land fared better than urban households. Examining the same price spike and using nationally representative rural household data from Bangladesh, Balagtas et al. (2012) found an increase in poverty rates and demonstrated that the determinants of poverty change over time. And using nationally representative data from South Africa, Jacobs (2010) found that household hunger levels increased as a result of the food price and financial crises of 2007-2009. These studies employed various other methodologies and focused on different household-level outcomes, but like the present chapter, they were all able to observe (and estimate) behavioral responses to large increases in food prices (given the available data) rather than through modeling assumptions or simulations.

\subsection{Data}

Our primary data are from the NRVA 2007/2008, which was conducted by Afghanistan's Central Statistics Organization and Ministry of Rural Rehabilitation and Development. The survey was administered between August 2007 and September 2008 and covered over 20,500 households (over 150,000 individuals) in 2572 communities in all 34 provinces of Afghanistan. The long time frame made it possible to obtain seasonally representative estimates of household food security and allowed for the coverage of conflict areas.

The sample was selected based on a stratified, multistage design. The survey was stratified explicitly, geographically, and implicitly over time. ${ }^{5}$ The 11 provinces with the most populous provincial centers were each stratified into urban and rural areas. The remaining provinces were treated as separate rural strata, and the nomadic Kuchi population was treated as a separate stratum. The stratification resulted in 46 domains or strata. In the first stage of selection, 2441 primary sampling units (PSU) from urban- and rural-settled populations and 131 PSUs from Kuchi populations were drawn. In the second and final stage, eight households were selected from each PSU.

The implicit stratification over time was a key element of the survey design. The population frame was sorted both spatially and temporally to ensure that (with a systemic interval selection) the selected sample would be seasonally

\footnotetext{
${ }^{5}$ The population frame is based on a 2003-2005 national household listing.
} 
representative. ${ }^{6}$ Thus each quarterly sample of the NRVA survey is representative at the national level. In a country where agriculture is an important form of livelihood, seasonal variations in consumption patterns are to be expected; thus it is critical to capture nationally representative measures of household food security throughout the year. Appendix Table 21.10 displays key demographic, educational and health, and infrastructure indicators across the four quarters. While we observed some statistical differences in means across quarters, there is little evidence of systematic differences in the samples based on these generally time-invariant characteristics.

Another key feature of the survey was the yearlong fieldwork, which allowed for coverage of conflict-affected areas. The enumerators informally secured permission from local leaders in conflict areas, and when a primary sampling unit (PSU) was considered too dangerous to interview at the scheduled time, it would be reconsidered at a later date within the quarter, instead of being replaced immediately. This flexible design helped to ensure a low replacement rate. While the majority of replacements were due to security issues, only 68 PSUs were replaced from the planned 2441 PSUs in the sample design (less than $3 \%$ replacement rate). ${ }^{7}$ It is often difficult to obtain reliable data from conflict areas; thus the current analysis provides a rare insight into the relationship between food insecurity and conflict.

The household survey module includes 20 sections -6 administered by female interviewers to female household members and 14 administered by male interviewers to the male household head. The enumerators traveled in teams of two (one male and one female) since females are not able to travel by themselves in Afghanistan and because it is important that interviews be conducted between individuals of the same sex due to the strong cultural norms regarding separation between the sexes outside the family. Households were asked questions about consumption, demography, housing infrastructure and access, maternal and child health, education, income sources, agriculture and livestock, migration and remittances, and assets and credit.

To collect data on nonfood expenditure, respondents (male and female, depending on the category) were asked about the amount of afghani spent on various items or categories of items over the past month or year (depending on the category). Below we describe how we constructed the nonfood expenditure measures; in the caveats section, we discuss potential biases that could result from the various recall periods.

The food consumption data include the frequency and quantity of consumption of 91 food items over the previous week, including food bought on the market, produced, or obtained through other methods like food aid or gifts. The NRVA's broad coverage of foods, including seasonal varieties, allows for better calculation of caloric and nutrient intake than surveys which take fewer items into account.

Household consumption data do not typically account for food wastage, and thus estimates of food intake may be larger than actual values. We assume that in a poor country like Afghanistan, wastage is relatively small and therefore not a significant

\footnotetext{
${ }^{6}$ See Kish (1965, pp. 235-236) for a discussion of implicit stratification.

${ }^{7}$ Replacement PSUs were primarily selected from the nearest secure district.
} 
source of bias. Generally, in low-income countries like Afghanistan, much less food is wasted at the consumer level than at early and middle stages of the food supply chain (FAO 2011). A potentially more challenging concern is if wastage is correlated with price volatility. If the amount of food wasted is negatively correlated with food prices (as might be expected), then the coefficients of the price of wheat flour in the regressions that examine food consumption and caloric intake will have positive biases. ${ }^{8}$ However, we maintained the assumption that wastage is low and any potential bias is small.

The price data were obtained from a district price survey, which included prevailing prices of the food items included in the consumption section as well as domestic and imported grains and fuel. The local price data were important for obtaining accurate estimates of price effects in a mountainous country with poor infrastructure, where transportation and transaction costs vary greatly.

Finally, we also used confidential geo-coded conflict data obtained from the United Nations Department of Safety and Security (UNDSS) that cover the survey time frame from August 2007 to September 2008. The UNDSS collects information on fatalities, injuries, and, in general, violent incidents. According to the official UN definition, violent incidents include the following: abduction, air strike, armed clash, arrest, assassination, finding a weapons' cache, confrontation/dispute, crime, demonstration, IED (improvised explosive device) detonation, finding an IED, information, intimidation, mine/UXO (unexploded explosive ordnance) incident, narcotic incident, standoff attack, suicide attack, and others. Over the survey year, there were 506 violent incidents across the country, with 421 associated fatalities and 322 associated injuries.

\subsubsection{Measures of Nonfood-Based Coping Responses}

Our main measures of nonfood-based coping responses were nonfood expenditures. We constructed a measure of real per capita monthly nonfood expenditure, total expenditure, and expenditure for eight major categories: health, education, clothing (including shoes), grooming (including laundry fees), tobacco and cigarettes, transportation, communication, and culture. ${ }^{9}$ We also constructed several complementary measures: recent migration of household members, selling of livestock (which are productive assets), enrollment of children in school (at the individual level), and a categorical variable denoting the frequency with which households report buying food on credit (1-4: never, sometimes, often, and always). We classified the last

\footnotetext{
${ }^{8}$ The sign of the bias is determined by the product of the correlation coefficients of (1) food waste and wheat flour prices and (2) food waste and food expenditure or caloric intake. If both correlation coefficients are negative, then their product, and thus the sign of the bias, is positive.

${ }^{9}$ The recall period for grooming, tobacco and cigarettes, and communication expenditures is the past 30 days. The recall period for health, education, clothing, and culture expenditures is the past 12 months.
} 
measure as nonfood based because it relates to credit and debt rather than changes in actual food consumption. Alternatively, one could classify this measure as a foodbased coping strategy. In this chapter, however, we adopted the FAO categorization, in which food-based coping strategies correspond to changes in the quantity or quality of food consumed (FAO 2008). To convert nominal values into real values, we used the nonfood price index from the Consumer Price Index for Afghanistan. The index accounts for temporal, but not spatial, differences in prices.

\subsubsection{Measures of Food-Based Coping Responses}

We constructed three main measures of household food-based coping responses for use as dependent variables in the regression analysis: food consumption, per capita daily caloric intake, and household dietary diversity. The first, real monthly per capita food consumption is an informative measure of household well-being and a core component of poverty indicators. It has been used as a measure of food security in the literature as well; for an early example, see Green and Kirkpatrick (1982). The second is a widely used measure of health and undernourishment. And the third has been shown to be linked to the nutritional status of children and adults (Arimond and Ruel 2004; Ruel 2003; Steyn et al. 2006) and has been lauded as a cost-effective, quick, informative measure of food security (Headey and Ecker 2013; Tiwari et al. 2013). Although much of the economics literature has focused on caloric intake as a nutritional measure and a measure of food security, there is a growing recognition of the importance of dietary quality to short- and longterm health, cognition, and productivity outcomes; therefore, we incorporated and highlighted measures of dietary quality in our work.

The real value of food consumption (in afghani) is calculated by combining quantity data from the consumption module with price data from a district price survey. Food consumption data include food which was bought, produced, or obtained through other methods, e.g., food aid and gifts. Weekly values were multiplied by 4.2 to get monthly values. Prices were matched by month, item, and district. Since not all food items were available in all district markets at all times of the year, we imputed the missing elements to obtain a complete price matrix. ${ }^{10} \mathrm{We}$ calculated average prices for domestic and imported varieties separately to account for differences in price and quality between domestic and imported wheat and rice. ${ }^{11}$ The value of the expenditure on food away from home was included in the

\footnotetext{
${ }^{10}$ The imputation process filled in missing values using the first-feasible methodology according to the following order: (1) median of the 20 nearest neighboring districts of that month, (2) province median of that month, (3) national median of that month, (4) median price of 20 neighboring districts of the quarter, (5) province median of that quarter, and (6) national median of that quarter.

${ }^{11}$ The survey includes questions about the percentages of imported wheat and rice consumed; these percentages were used to calculate the total expenditure on these items.
} 
calculation of food consumption, but it was not included in the calculation of caloric intake since quantity data on such food were not collected.

We adjusted the food consumption estimates to take into account spatial and temporal variation in prices in order to identify correctly those households that fall below the food poverty threshold (described below) and, in the regression analysis, to estimate the impact of the price increases on real values. We used a Laspeyres price index estimated by quarter for each region. The food price index was based on a reference bundle of goods consumed by relatively poor households; the reference bundle was constructed to reflect regional diversity in consumption patterns. There are eight regions in Afghanistan, as defined in Islamic Republic of Afghanistan and World Bank (2011). Real food consumption is relative to the chosen base: urban areas in the Central Region in quarter 1; the capital, Kabul, is located in the Central Region.

We used the FAO Food Composition Tables for the Near East to convert daily food quantities into kilocalories; we then divided the daily caloric intake by the effective household size to get the per capita daily caloric intake. ${ }^{12}$ The effective number of household members incorporates guests eating meals within the home and decreases when household members do not regularly take meals at home. ${ }^{13}$ The effective number of household members is greater than the household size for the richer households and lower for the poorer households.

To measure household dietary diversity, we used the food consumption score (FCS), which is developed by the World Food Programme (WFP) and used in food security assessments throughout the world. It is a weighted sum of the frequencies with which households consume foods within eight food groups over the previous week. ${ }^{14}$ The food groups include grains, pulses, vegetables, fruit, meat/fish, milk/dairy, sugar, and oil/fat. Higher scores denote a more varied diet and are suggestive of a higher-quality diet with a potential for higher micronutrient intake.

It is challenging to account for food consumption and expenditure on meals away from home. The survey asked how many meals were eaten away from home by household members over the past 7 days and the value of food and drinks consumed outside the home over the past 30 days; however, there was no information on

\footnotetext{
${ }^{12}$ Spices, water, and "other" foods do not contribute to total calories. USDA sources were used for a few items that were not available in the FAO tables.

${ }^{13}$ Some studies use household size to calculate per capita amounts, but the prevalent custom of sharing meals in Afghanistan makes it important to account for guests eating meals from the household cooking pot. We do not use equivalency scales to account for differences in consumption of adults and children when calculating measures of well-being but rather opt to include variables for household composition directly into the regression model to control for such differences.

${ }^{14}$ Weights for the food groups range from 0.5 to 4 based on nutrient density. Condiments receive zero nutritional weight. Frequencies are truncated at 7 for each food group. The measure ranges from 0 to 112.
} 
what food is consumed outside the household..$^{15}$ Therefore, we did not include any calories from food eaten away from home in the caloric intake calculation, and food consumed away from home also did not impact the food consumption score. These measures may not accurately capture all food consumed by members of the household. Without detailed food diaries however, it is difficult to obtain sufficient information. Note that food away from home constituted about $2 \%$ of total food expenditure on average; it accounts for less than half a percent for the poorest $20 \%$ of the population and about $4 \%$ for the richest $20 \%$ of the population.

\subsubsection{Summary Statistics}

The effective sample size of our analysis was 20,483 households. ${ }^{16}$ Table 21.1 displays the population means of key household characteristics for the full sample over the survey year. On average, households had 8.6 members living in about 3.6 rooms (or tents for the Kuchi population). A typical household consisted of 2.1 men, 2 females, and 4.5 children (under 16). The head of a household was on average about 45 years old; nearly all were married, and most of them were illiterate. Approximately $80 \%$ of the households resided in rural areas. Very few households reported having members who migrated or reported selling livestock recently (over past year). Finally, about $16 \%$ of the households reported that they were often or always purchasing food on credit; the remainder of the households reported that they had never $(27 \%)$ or sometimes (57\%) purchased food on credit. Approximately $59 \%$ of the households reported borrowing money over the prior year; and $70 \%$ of those households reported that the money was used mainly to purchase food.

Table 21.2 displays the population means for the total nonfood and the total food expenditure as well as caloric intake and dietary diversity by quarter and for the survey year. The raw data revealed the instability of household food security in Afghanistan; we observed large declines in food expenditure, caloric intake, and dietary diversity, with the worst levels observed in quarters three and four. Changes in nonfood expenditures were less stark, although the nonfood expenditures on many categories declined over the survey year. Overall, these patterns lend support to the evidence that the poverty rate had increased, as reported by the Government of

\footnotetext{
${ }^{15}$ We use the questions on meals eaten outside the home and the value of food and drinks consumed to calculate average expenditure on food away from home for each household, which is included in the total value of food consumption.

${ }^{16}$ The household response rate was $99.8 \%$, and the PSU replacement rate was $3 \%$. Thirty-two households were dropped due to missing female questionnaires; all of these households were located in four communities, suggesting a relatively small systematic error in field operations. Fifty-two households were dropped due to missing consumption data, and seven households were dropped due to missing asset data. Information on household size was missing for one household, and therefore, the household was dropped because per capita measures of consumption and food security could not be calculated.
} 
Table 21.1 Household characteristics

\begin{tabular}{l|l}
\hline Age of household head & 44.87 \\
\hline Number of males & 2.09 \\
\hline Number of females & 2.01 \\
\hline Number of children under 16 years & 4.51 \\
\hline Share of households with married head & 0.95 \\
\hline Share of households with literate head & 0.32 \\
\hline Share of agricultural households & 0.57 \\
\hline Share of households in rural areas & 0.80 \\
\hline Share of households in plain areas & 0.74 \\
\hline Share of households in plateau areas & 0.22 \\
\hline Share of households in mountainous areas & 0.39 \\
\hline Share of households with recent migrant & 0.08 \\
\hline Share of children between 8 and 16 years in school & 0.95 \\
\hline Share of households purchasing food on credit often or always & 0.16 \\
\hline Share of households that sold live livestock recently & 0.03 \\
\hline Total observations & 20,483 \\
\hline
\end{tabular}

Source: NRVA 2007/2008. Note: Estimated population-weighted means. Share of children in school is derived from individual child-level data set with 35,893 observations

Table 21.2 Population statistics by quarter and over survey year

\begin{tabular}{l|l|l|l|l|l}
\hline $\begin{array}{l}\text { Real per capita monthly expenditure } \\
\text { (afghani) }\end{array}$ & $\begin{array}{l}\text { Quarter 1 } \\
\text { (fall) }\end{array}$ & $\begin{array}{l}\text { Quarter 2 } \\
\text { (winter) }\end{array}$ & $\begin{array}{l}\text { Quarter 3 } \\
\text { (spring) }\end{array}$ & $\begin{array}{l}\text { Quarter 4 } \\
\text { (summer) }\end{array}$ & $\begin{array}{l}\text { Survey } \\
\text { year }\end{array}$ \\
\hline Total & 2022.00 & 1718.78 & 1519.39 & 1477.69 & 1672.31 \\
\hline Food & 1201.19 & 961.47 & 789.45 & 797.60 & 928.65 \\
\hline Nonfood & 586.91 & 549.62 & 496.20 & 462.06 & 521.01 \\
\hline Health & 80.70 & 74.38 & 77.32 & 81.41 & 78.44 \\
\hline Education & 7.38 & 5.56 & 5.18 & 5.27 & 5.80 \\
\hline Clothing & 98.17 & 90.19 & 89.11 & 90.85 & 91.90 \\
\hline Grooming & 77.81 & 60.11 & 49.86 & 54.15 & 59.97 \\
\hline Tobacco and cigarettes & 9.49 & 8.25 & 8.09 & 8.22 & 8.48 \\
\hline Transportation & 94.59 & 79.92 & 79.48 & 81.86 & 83.63 \\
\hline Communication & 28.67 & 26.09 & 23.60 & 23.49 & 25.35 \\
\hline Culture & 109.86 & 96.04 & 91.27 & 91.47 & 96.73 \\
\hline Daily per capita caloric intake & 2885 & 2725 & 2446 & 2387 & 2601 \\
\hline Food consumption score & 68 & 61 & 58 & 58 & 61 \\
\hline
\end{tabular}

Source: NRVA 2007/2008. Note: Population-weighted means. Real values reflect adjustments for spatial and temporal price differences, covering 13 months of field work. Food expenditure includes the value of home production, gifts, and food aid; see text for details

Afghanistan; the official poverty rate increased from $23.1 \%$ in fall 2007 to $46 \%$ in summer 2008 (MoE Islamic Republic of Afghanistan and the World Bank Economic Policy and Poverty Sector 2010).

To further explore how the food security status of the most vulnerable households was affected by the wheat flour price increases, we controlled for heterogeneous 
Table 21.3 Population statistics across the distribution and across the survey year

\begin{tabular}{|c|c|c|c|c|c|c|c|c|c|c|}
\hline Quantile & 10th & 20th & 30th & 40th & 50th & 60th & 70th & 80th & 90th & $\mathrm{Me}_{\mathrm{i}}$ \\
\hline \multicolumn{11}{|l|}{ Full survey year } \\
\hline $\begin{array}{l}\text { Real per capita month } \\
\text { consumption }\end{array}$ & 474 & 572 & 650 & 727 & 810 & 903 & 1026 & 1198 & 1514 & 92 \\
\hline Daily per capita caloric intake & 1695 & 1937 & 2113 & 2279 & 2441 & 2629 & 2861 & 3166 & 3688 & 2601 \\
\hline Food consum & 34 & 42 & 49 & 56 & 61 & 66 & 71 & 78 & 88 & 61 \\
\hline \multicolumn{11}{|l|}{ Quarter 1} \\
\hline & 552 & 685 & 818 & 937 & 1058 & 1201 & 1371 & 1585 & 2020 & 1201 \\
\hline Daily per capita caloric intake & 1740 & 1992 & 2236 & 2452 & 2679 & 2938 & 3240 & 3628 & 4262 & 2885 \\
\hline Food consu & 40 & 50 & 57 & 64 & 69 & 74 & 79 & 86 & 95 & 6 \\
\hline \multicolumn{11}{|l|}{ Quarter 2} \\
\hline & 492 & 600 & 684 & 771 & 855 & 954 & 1083 & 1264 & 1566 & 96 \\
\hline Daily per capita caloric intake & 1764 & 2030 & 2234 & 2414 & 2589 & 2780 & 3022 & 3322 & 3835 & 2725 \\
\hline Food consu & 34 & 41 & 47 & 55 & 60 & 66 & 72 & 80 & 92 & \\
\hline \multicolumn{11}{|l|}{ Quarter 3} \\
\hline $\begin{array}{l}\text { Real per cap } \\
\text { consumptior }\end{array}$ & 446 & 528 & 594 & 653 & 720 & 794 & 880 & 1004 & 1190 & 789 \\
\hline Daily per capita caloric intake & 1663 & 1899 & 2062 & 2217 & 2351 & 2499 & 2678 & 2937 & 3311 & 2446 \\
\hline Food consumption score & 32 & 40 & 47 & 53 & 58 & 63 & 69 & 75 & 83 & 5 \\
\hline \multicolumn{11}{|l|}{ Quarter 4} \\
\hline $\begin{array}{l}\text { Real per capita monthly food } \\
\text { consumption }\end{array}$ & 458 & 545 & 614 & 674 & 735 & 806 & 884 & 998 & 1195 & 798 \\
\hline Daily per capita caloric intake & 1610 & 1873 & 2023 & 2144 & 2279 & 2426 & 2617 & 2861 & 3263 & 2387 \\
\hline Food consumption score & 33 & 42 & 49 & 55 & 59 & 63 & 67 & 71 & 79 & 5 \\
\hline
\end{tabular}

Source: NRVA 2007/2008. Note: Population-weighted estimates at each decile and at the mean, for the survey year and by quarter

price effects on household food security based on a household's level of food security. In Table 21.3, we present the mean of real per capita monthly food consumption, daily per capita caloric intake, and household dietary diversity at each decile (for the survey year and by quarter).

Nearly $30 \%$ of the Afghan households failed to meet the conventional nutritional benchmark of 2100 calories per day, while those at the top of the calorie distribution were well above the threshold. The mean per capita daily caloric intake was approximately 2601. ${ }^{17}$ This estimate is in line with worldwide calorie estimates obtained using macroeconomic data; between 2007 and 2009, the average daily calories per capita were 2810 in the world, 2670 in developing countries, and 2380

\footnotetext{
${ }^{17} \mathrm{We}$ assumed the figure has been slightly overestimated due to some food waste and telescoping. For example, Deaton and Kozel (2005) noted that in the case of India, a 7-day food recall period produces higher daily food estimates than a 30-day recall period.
} 
in South Asia (excluding Afghanistan and Bhutan) (FAO 2012). ${ }^{18}$ The estimate is also in line with the estimates obtained using nationally representative household data for the region; daily calories per capita was between 2392 and 2593 in Pakistan during the period from 2005 to 2008 (Friedman et al. 2011), and this figure was 2536 in Nepal in 2010/2011 (National Planning Commission and Central Bureau of Statistics 2013).

The mean food consumption score was 61, ranging from 34 at the bottom decile to 88 at the top decile. The WFP uses 48 as a cutoff for an acceptable diet in countries like Afghanistan where most households consume staples and oil every day. Under this categorization, approximately $80 \%$ of the population in Afghanistan has acceptable diets, which is consistent with the food security assessments conducted by the WFP on several other developing countries in recent years. Based on their assessments, the percentages of households with acceptable diets are as follows: Uganda, $78 \%$ in 2013; Rwanda, $79 \%$ in 2012; Malawi, $75 \%$ in 2010/2011; Cambodia, $81 \%$ in 2008; and Pakistan, $82 \%$ in $2008 .{ }^{19}$ Recent work has suggested that the cutoff points of the FCS classifications may be too low, for example, when compared with estimates of calorie deficiency (Weismann et al. 2009).

Households at the top of all three distributions experienced the largest declines in food security in percentage terms, while those households at the bottom of the distributions experienced smaller declines in food security. It is important to note that the most food-insecure households were consuming relatively poor diets, and even small declines in quantity and quality of food consumed could have major repercussions on the short- and even long-term nutrition of children in their early development stages.

\subsubsection{Price Data}

Our analysis focused on the price of domestic wheat flour, the form of wheat most commonly purchased by households. Most wheat is consumed in the form of naan, a type of local unleavened bread that is prepared by households after purchasing either refined wheat flour or whole grain wheat (Chabot and Dorosh 2007). Wheat and other grains constituted $48 \%$ of food expenditure and $70 \%$ of calories consumed.

Table 21.4 displays the mean price of domestic wheat flour by quarter and over the survey year; it also includes other important commodities that we used in the

\footnotetext{
${ }^{18}$ FAOSTAT provides estimates of dietary energy supply (in kilocalories per person per day), averaged over 3 years and weighted by population. These estimates were calculated using macroeconomic supply data and may be less reliable than estimates derived from household survey data.

${ }^{19}$ Estimates were drawn from WFP reports, available at http://www.wfp.org/food-security/ assessment-bank.
} 
Table 21.4 Average prices by quarter and over the survey year

\begin{tabular}{l|c|c|c|c|c}
\hline & $\begin{array}{l}\text { Quarter 1 } \\
\text { (fall) }\end{array}$ & $\begin{array}{l}\text { Quarter 2 } \\
\text { (winter) }\end{array}$ & $\begin{array}{l}\text { Quarter 3 } \\
\text { (spring) }\end{array}$ & $\begin{array}{l}\text { Quarter 4 } \\
\text { (summer) }\end{array}$ & $\begin{array}{l}\text { Survey } \\
\text { year }\end{array}$ \\
\hline Price of domestic wheat flour & 18.09 & 23.52 & 34.19 & 36.51 & 28.45 \\
\hline Price of vegetable oil & 64.81 & 76.93 & 88.90 & 91.70 & 81.16 \\
\hline Price of domestic rice & 33.93 & 33.99 & 46.16 & 55.29 & 42.77 \\
\hline Price of lamb & 182.34 & 186.20 & 189.28 & 180.27 & 184.44 \\
\hline Price of milk & 23.44 & 25.66 & 27.23 & 30.75 & 26.94 \\
\hline Price of kerosene & 43.15 & 45.77 & 46.82 & 55.48 & 48.12 \\
\hline
\end{tabular}

Source: NRVA 2007/2008. Note: Population-weighted means. Prices are in afghani per kilogram or liter

regression analysis to control for simultaneous price increases. ${ }^{20}$ The NRVA price data showed patterns which are similar to the FAO GIEWS data in Fig. 21.1, with a marked increase in prices in quarter three of the survey. We chose milk, lamb, rice, and vegetable oil because they (1) represent several key food groups and (2), along with wheat flour, make up a large percentage of monthly household food expenditure; for example, the relatively poor (20th to 50th quantile of the total consumption distribution) spend $80 \%$ of their food expenditure on these five food items. We included kerosene because it is the most commonly used cooking fuel.

A major limitation of this analysis is that we could not disentangle the impacts of the price increases due to three different sets of conditions: the 2007/2008 global food crisis, the 2008 poor harvest, and seasonal variations due to weather and harvest quality. Therefore the results below identify the effect of overall price changes on household food security. If food prices follow a cyclical pattern, dropping in the months after harvest (September-October) and slowly increasing throughout the year as stocks deplete, then we would expect that the price increases were due to the global food crisis and compounded by the cyclical domestic pattern. However, we do not believe that seasonality was a major driver of the price increases. (Recall that Fig. 21.1 displays the retail prices of wheat flour in four major urban centers from 2002 to 2013.) The 2008 price spike was larger than the observed seasonal variation in prices by orders of magnitude. In fact, there is little evidence that monthly prices fluctuate drastically throughout the harvest calendar. Because of transportation costs, it is likelier that prices in remote areas experience greater fluctuations. However, if seasonal wheat flour price patterns were indeed very significant in Afghanistan, we would have observed them in these major urban areas in the years prior to the 2008 spike, but we do not.

The ability to disentangle the causes of the price changes from each other would presumably alter the approach to policy prescription. For example, if the price changes are local rather than global, the policy response would be more

\footnotetext{
${ }^{20}$ Prices were aggregated to the stratum level in order to mitigate potential measurement error in district-level prices. Strata are based on urban and rural designation within provinces.
} 
targeted, such as releasing grain from reserves to the affected area. If the price changes are global, then the appropriate policy response may be more oriented toward macroeconomic and trade policies. If the price changes are due to anticipated seasonal variations, policies aimed at helping households to smooth consumption, such as improved grain storage, might be desirable. Whereas if the price change is due to a fully unanticipated price shock, which we believe to be largely the case, then the policy response might be more oriented toward short-run safety net programs that focus on nutrition.

\subsection{Methodology}

We estimated the following reduced-form model of the impact of the wheat flour price increases on measures of household nonfood-based and food-based coping responses:

$$
\begin{aligned}
& \text { ihs }\left(\operatorname{resp}_{\mathrm{h}}\right)=\beta_{0}+\beta_{1} \log \left(\text { price wheat flour }_{\text {apq }}\right)+\theta \log \left(\text { prices }_{\text {apq }}\right) \\
& +\alpha \mathrm{HH}_{\mathrm{h}}+\delta \mathrm{DIST}_{\mathrm{dq}}+\eta \log \left(\text { conflict }_{\mathrm{qp}}\right)+\Pi_{\mathrm{p}}+\varepsilon_{\mathrm{h}}
\end{aligned}
$$

where $\mathrm{h}$ denotes household, a denotes area (urban or rural), d denotes district, $\mathrm{p}$ denotes province, and q denotes quarter. resp represents one of the household coping responses described above. Prices represent a vector of commodity prices, $\mathrm{HH}$ represents a vector of household characteristics, DIST represents a vector of districtlevel variables, $\Pi$ denotes province dummy variables, and $\varepsilon$ is an idiosyncratic error term.

Instead of transforming the dependent variable by taking the logarithm (with or without adding some arbitrary small value to the zero values), we used the inverse hyperbolic sine (IHS) transformation, which reduces the importance of extreme observations (similar to taking logs) but has the additional benefit of being well defined at zero values. The IHS transformation, first proposed by Johnson (1949), was introduced to econometrics by Burbidge et al. (1988). ${ }^{21}$ It has been used as an alternative to $\log$ transformations for the dependent variable (Burbidge et al. 1988; MacKinnon and Magee 1990) and for explanatory variables (Layton 2001) with variables that can take on zero or negative values. Results can be interpreted in percentage terms, as in log models.

In order to isolate the effect of changes in wheat flour prices, we controlled for simultaneous price increases in other important commodities since (1) household purchasing decisions are based on relative price movements, and (2) omitting such

\footnotetext{
${ }^{21}$ The IHS function is defined as $\sin h^{-1}=\log \left(x+\left(x^{2}+1\right)^{\frac{1}{2}}\right)$.
} 
variables could bias our coefficient of interest. ${ }^{22}$ The price vector includes the prices of milk, lamb, rice (a potential substitute for wheat flour, though not commonly consumed in Afghanistan), vegetable oil, and kerosene for reasons mentioned above.

We included the following household characteristics: dummy for agricultural households (households who report owning or operating agricultural land); log values of durable assets, housing, and livestock; age of household head; dummy for households in which heads are literate; dummy for households in which heads are married; and, separately, the numbers of men, women, and children. We included the agricultural household dummy because these households are able to produce their own food and are thus less reliant on the market. Furthermore, some of these households could benefit from increased wheat flour prices if they are net sellers of wheat. We included the household composition variables to control for differences in consumption requirements between children and adults and for economies of scale in consumption. ${ }^{23}$

The asset values were intended to control for wealth effects and were assumed to be quasi fixed in the short run. Poorer and richer households may have different constraints on their abilities to cope with price increases. For example, richer households have more assets to sell in order to smooth consumption. In a recent contribution, Carter and Lybbert (2012) showed that poorer households are unable to smooth total consumption as well as richer households when responding to weather shocks. ${ }^{24}$ Additionally, richer households may have more food-based coping strategies available since they usually consume a more diversified diet of more expensive foods; they then have the option to move toward cheaper foods and food groups as prices increase.

The value of durable goods was estimated based on a detailed inventory of household assets; it accounted for depreciation and the opportunity cost of the funds tied up in the good. The value of housing was estimated using a hedonic model based on characteristics of the structure, as well as the location, to derive an imputed rental value from this. ${ }^{25}$ All values are in real afghani.

\footnotetext{
${ }^{22}$ Given that food prices are often positively correlated with each other and negatively correlated with some of the dependent variables, like food expenditure and caloric intake, omitting the other food price variables would lead to a negative bias on the coefficient of the log of wheat flour price.

${ }^{23}$ An alternative approach to account for such differences employs equivalency scales that take into account nutritional requirements based on age and, sometimes, gender when calculating per capita measures. For an early example, see Buse and Salathe (1978).

${ }^{24} \mathrm{It}$ is often assumed the poorer households smooth consumption in the face of shocks; however, using a poverty trap model, Carter and Lybbert (2012) show that below a critical wealth level, poorer households smooth (or protect) assets rather than consumption due to high marginal values of assets and the potential of future-negative shocks.

${ }^{25}$ The estimated housing value is the log of imputed, monthly rental value based on a hedonic model of the housing structure. The log value of assets is a self-assessed valuation based on a list of 13 assets including items such as stoves, refrigerators, radios, sewing machines, and bicycles. For details of the estimation, see Islamic Republic of Afghanistan, Central Statistics Organization (Islamic Republic of Afghanistan et al. 2011).
} 
At the district level, we included dummies for topography-plateau and mountainous areas (plains areas make up the excluded category). Topographical characteristics are related to both agricultural yields and access to markets and thus can affect a household's level of food security. At the province-quarter level, we included a measure of conflict since the level of conflict can be correlated with food prices, as well as household coping responses. ${ }^{26}$ We used the ratio of the number of individuals killed or injured in each province during each survey quarter to the province population (in tens of thousands) as our measure of conflict. Finally we also included province dummy variables to control for observable and unobservable time-invariant province-level factors, which could confound the results.

\subsubsection{Model Estimation}

We used two estimation techniques. For the nonfood-based coping responses, we estimated the parameters above using ordinary least squares (OLS), a commonly used estimator that provides the marginal effect for the mean household. For the food-based coping responses, we estimated the model using both OLS and the unconditional quantile regression (UQR) estimator proposed by Firpo, Fortin, and Lemieux (2009b, hereafter referred to as FFL). The UQR estimator allows the marginal effects to vary based on a household's location on the unconditional distribution of the dependent variable. ${ }^{27}$ From a policy perspective, we were interested in heterogeneous price effects on vulnerable households (e.g., those at the bottom of the calorie distribution); we were less interested in how the price effects vary for those who spend a lot or a little on, for example, clothing, and thus we limited the UQR analysis to the food-based coping responses.

For our OLS estimates, we used a standard Huber-White correction to estimate the sampling variance, which allows for the correlation of the residuals within PSUs. The standard errors are also corrected for stratification. For the UQR estimates, we used a PSU-level bootstrap (1000 replications) that accounted for the correlation of the residuals within the PSUs but did not account for the stratification.

\footnotetext{
${ }^{26}$ In D'Souza and Jolliffe (2013), we examined the relationship between food security and conflict in Afghanistan. We found strong evidence of a negative relationship, as well as evidence that households in provinces with more conflict experience muted declines in food security as a result of wheat flour price increases. We posited that the latter result is because those households were more disconnected from markets (and may have had better coping mechanisms).

${ }^{27} \mathrm{By}$ construction, OLS estimates are constant over the entire distribution of the dependent variable and thus cannot elucidate heterogeneous effects for subsets of households. Ex ante, we do not know whether the UQR estimator will provide qualitatively different information than OLS. There is some evidence that the conditional quantile regression estimator provides substantively different estimates. For example, Koenker and Bassett (Koenker and Bassett 1982) show that in the presence of a heteroskedastic error distribution, the quantile estimator will typically differ from the OLS estimator.
} 
The UQR estimator was proposed in 2009 and is becoming a more commonly used tool in policy analysis. The UQR estimator is based on influence functions, which were introduced by Hampel et al. (1988) as a tool in robust estimation techniques. ${ }^{28}$ Using notation (largely) defined by FFL, consider some distributional statistics, $v\left(F_{y}\right)$, such as the median, inter-quantile range, or any quantile. The influence function, $\operatorname{IF}\left(Y ; \nu, F_{y}\right)$, represents the influence of an individual observation on the distributional statistic, $v\left(F_{y}\right)$, where $Y$ is the dependent variable. A key innovation by FFL is that they added $v\left(F_{y}\right)$ to the influence function to center it. This new function is called a recentered influence function (RIF). By design, the expectation of the RIF is the value of the distributional statistic, or more formally, $E\left(\operatorname{RIF}\left(Y ; v, F_{y}\right)\right)=v\left(F_{y}\right){ }^{29}$

FFL defined $m_{\tau}(X)=E\left(\operatorname{RIF}\left(Y ; \tau, F_{y}\right) \mid X\right)$ as the unconditional quantile regression model. ${ }^{30}$ The RIF regression parameter estimates are unconditional quantile marginal effects (UQME) or partial derivatives with respect to the price of wheat flour, as described by the following expression:

$$
\frac{\partial Q_{\mathrm{fs}}(\tau)}{\partial \text { price wheat flour }}
$$

where $Q_{\mathrm{fs}}$ is the unconditional quantile function of our food-based coping response measures, and $\tau$ represents quantiles of the unconditional distribution. For our analysis, we estimated the marginal effects at all deciles (10th, 20th, .., 90th) of the food-based coping response distributions while controlling for the covariates in our model specification. The large observed variations in our food-based coping response measures (Table 21.3) suggested that the UQME could differ for households at the bottom and top of the distributions.

An alternative to the UQR is the conditional quantile regression (hereafter CQR) estimator (Koenker and Bassett 1978), which allows behavioral responses to vary across the distribution of the dependent variable after conditioning on the observed covariates (e.g., see Chamberlain 1994). This estimator is based on the conditional population distribution; however, policy questions are typically phrased

\footnotetext{
${ }^{28}$ Robust statistics are statistics and estimators that are not influenced heavily by deviations from model assumptions nor influenced by single observations. Influence functions provide a formal way of measuring the extent to which a particular estimator is affected by a single observation in the sample.

${ }^{29}$ This is in contrast, for example, to the least absolute deviation (LAD) estimator, whereby the expectation of the $\mathrm{LAD}$ is not equal to the median.

${ }^{30} \mathrm{FFL}$ provided an estimation method based on transforming the dependent variable into the RIF and subsequently using OLS estimation. FFL have shown that this approach yields a consistent estimator of the average marginal: effect, $E[d \operatorname{Pr}[Y>\tau \mid X] / \mathrm{d} X]$, if $\operatorname{Pr}[Y>\tau \mid X=x]$, is linear in $x$. In order to estimate the standard errors, we followed the methodology proposed by FFL (Firpo et al. 2009b) and used a bootstrap estimator of the sampling variance. For readers who are interested, FFL (Firpo, Fortin, and Lemieux 2009a) derived the asymptotic properties of the estimator and provided the analytical standard errors.
} 
in the context of the unconditional distribution. ${ }^{31}$ For example, policymakers may be interested in knowing how price shocks affect the caloric intake of households at the bottom 20th percentile of the calorie distribution of the total population but not the conditional 20th percentile. A key distinction between the two is that the bottom of the unconditioned distribution consists of those who have very low caloric intake, whereas the conditioned distribution need not have low caloric intake (just low caloric intake conditional on their attributes, such as education level). The estimated marginal effects based on the unconditioned distribution can be valuable in targeting vulnerable people for safety net and poverty alleviation programs and in allocating resources in general. The results were robust to using this estimation technique; the observed signs and significance of the results were similar to those of our main results, although with some differences in the magnitudes.

\subsection{Results and Discussion}

The empirical analysis demonstrated that Afghan households employed both nonfood- and food-based coping strategies in response to the rapid increase in wheat flour prices in 2007/2008. We observed large reductions in real household expenditure across nearly all nonfood categories (Table 21.5). ${ }^{32}$ In response to increasing wheat flour prices, households reduced the amount spent on health, clothing, grooming, tobacco and cigarettes, transportation, communication, and cultural activities and practices. (They also reduced food expenditure, which we discuss in more detail below.)

The largest reduction was observed in health expenditure. Such reductions can have serious implications, but we have to be cautious when drawing strong inferences from these results since health expenditures are particularly challenging to interpret. In particular, a decline in health expenditure could indicate either a reduction in the need to treat health problems (i.e., better health) or a failure to take appropriate actions to treat an illness, which would lead presumably to much worse health outcomes. We argue that it is unlikely that a food price shock would be positively correlated with better health outcomes in a food-insecure country like Afghanistan; therefore, we assumed that food prices are either independent of or negatively correlated with health outcomes. In such cases, the observed reduction in health expenditures would indeed represent a coping behavior, whereby health needs are sacrificed to mitigate the shock to food consumption.

In the development literature, there is evidence that household behavior differs with respect to adult goods and child goods (Deaton and Paxson 1998). Expenditure

\footnotetext{
${ }^{31}$ As an exception to this assertion, Buchinsky (1994) provides an example in which the question posed is best answered by the CQR estimator and not something akin to the UQR. He examined the distribution of wages in the USA and, using the CQR estimator, provides insight into how wage inequality within groups (i.e., conditional on being in a specific group) changes over time.

${ }^{32}$ The tables display the coefficients of interest. Full results are available upon request.
} 


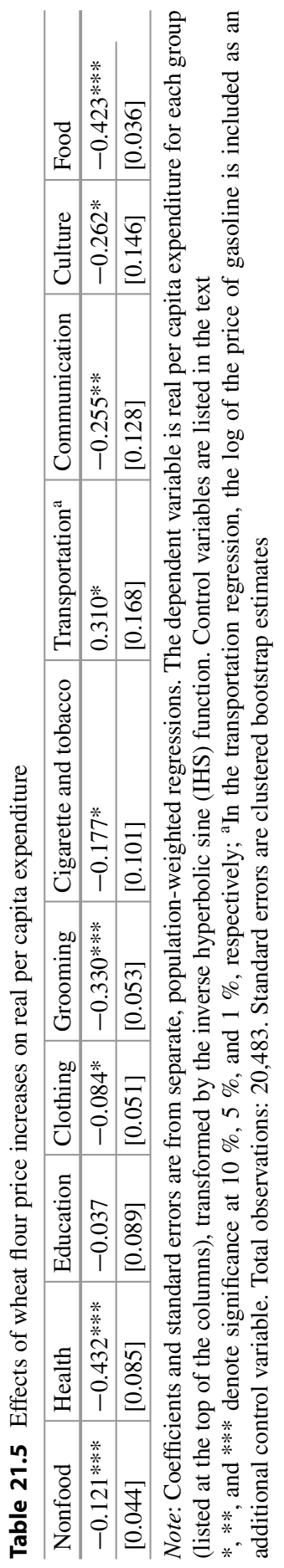


Table 21.6 Effects of wheat flour price increases on real per capita expenditure

\begin{tabular}{l|l}
\hline Adult clothing & Children's clothing \\
\hline$-0.113^{* *}$ & 0.092 \\
\hline$[0.051]$ & {$[0.074]$} \\
\hline
\end{tabular}

Note: Coefficients and standard errors are from separate, population-weighted regressions. The dependent variable is real per capita expenditure for each group (listed at the top of the columns), transformed by the inverse hyperbolic sine (IHS) function. Control variables are listed in the text. Total observations: 20,483. Standard errors are clustered bootstrap estimates

$*$, **, and $* * *$ denote significance at $10 \%, 5 \%$, and $1 \%$, respectively

Table 21.7 Effects of wheat flour price increases on other nonfood-based coping responses

\begin{tabular}{l|l|l|l}
\hline Sold livestock & Member migrated & Child in school & Purchased food on credit \\
\hline-0.014 & 0.007 & -0.0028 & $0.084^{* *}$ \\
\hline$[0.010]$ & {$[0.022]$} & {$[0.018]$} & {$[0.043]$} \\
\hline
\end{tabular}

Note: Coefficients and standard errors are from separate, population-weighted regressions. The dependent variable is indicator variable for action listed at the top of the column except for the last column; purchased food on credit is a categorical variable ranging from 1 (never) to 4 (always). Control variables are listed in the text. Total observations in column 1 and 2: 20,483; total observations in column 3: 15,924 (in the child-level regression). Standard errors are clustered bootstrap estimates

$*, * *$, and $* * *$ denote significance at $10 \%, 5 \%$, and $1 \%$, respectively

on grooming and on tobacco and cigarettes is typically categorized as adult goods, in addition to alcohol (not solicited in the NRVA survey) and adult clothing. The NRVA data allowed us to distinguish between clothing and shoes for adult and child. As shown in Table 21.6, we observed that households reduced the amount spent on adult clothing but did not make adjustments to child clothing expenditure. Furthermore, we did not find any effect of the price increases on education, which is a children's good. We interpret these results as evidence of Afghan households prioritizing - to a certain extent-child goods over adult goods in their nonfoodbased coping responses.

We did not find evidence of the use of other nonfood-based coping responses, with the exception of an increase in frequency at which households purchase food on credit (Table 21.7). ${ }^{33}$ We failed to find evidence of changes in the sale of livestock, in the migration of household members, and in school enrollment. Selling productive assets and migrating are extreme responses and could be potentially irreversible;

\footnotetext{
${ }^{33}$ The variable for purchasing food on credit is categorical, with values ranging from one to four. The displayed coefficient comes from an OLS model; however, the results are qualitatively similar to the coefficient from an ordered probit model.
} 
therefore, it is not surprising that households chose other coping strategies in lieu of these. As with educational expenses, households might have chosen to protect the investment in children by keeping them enrolled in school. Given the substantial decline in purchasing power, it is not surprising that households purchased food on credit more frequently; incurring even small amounts of debt could encumber a household and perpetuate the cycle of poverty.

Our nonfood-based coping response findings are consistent with the qualitative evidence presented by Lautze et al. (2002), who examined the coping strategies employed during times of drought in Afghanistan using focus groups across the country. In addition to reducing the quality, quantity, and frequency of their meals, Afghan households reported taking on debt and decreasing cultural celebration expenses related to Qurbani Eid. They also found that households sold off assets, increased migration, and increased their reliance on remittances.

For the food-based responses, we estimated the price effects for the mean household using OLS and for households at each decile of the unconditional distribution of the dependent variable using the UQR estimator (Table 21.7). For the mean Afghan household, we observed a large decline in real per capita food consumption and relatively smaller declines in calories and dietary diversity. We interpreted these results as a trade-off between quality and quantity that the household made in order to maintain energy levels in the face of declining purchasing power. More specifically, the mean Afghan household adjusted the composition of its diet in order to buffer the price shock to a certain extent (i.e., calories and diversity decline less than food expenditure).

Additionally, in the regressions above, we allowed the price effects to vary based on whether the household owned or operated agricultural land (the results are available in D'Souza and Jolliffe 2014). During periods of high food prices, these households may not be hurt as much as other households because they are able to produce their own food and are less dependent on the market. Furthermore, if they produce more food than they consume (i.e., net sellers), they can sell the food on the market and profit from the high prices. The NRVA data did not allow us to identify net sellers of wheat, and so we used a dummy for agricultural households. We did not find any strong systematic patterns that were consistent with the literature (i.e., agricultural households are better able to cope with the price increases). Nevertheless, the severe drought of 2008 would have limited the number of net sellers of wheat in Afghanistan at that time. The drought was the worst in the ten preceding years, with losses reported on both rainfed and irrigated wheat crops (Foreign Agricultural Service 2008).

The UQR estimates showed that increases in the wheat flour prices were associated with statistically significant declines in these food-based coping responses across much of the respective unconditional distributions. We observed the largest percentage decline in food consumption and calories for the Afghan households at the top of the respective distributions, with smaller declines observed as one 
moves lower on the distributions. ${ }^{34}$ At a very basic level, these households had more to give as they are well above food poverty thresholds and daily energy (calorie) requirements; they also hosted more guests and ate more away from home, on average, than poorer households. ${ }^{35}$

Households at the first decile of caloric intake were living below the threshold of energy requirements (with average daily per capita caloric intake of 1670) and presumably were unable to cut back on calories without suffering serious nutritional consequences. Accordingly we found no evidence of a decline in their caloric intake. Even those at the second decile experienced negligible changes, equivalent to less than a third of a standard naan (one piece of Afghan bread). Sulaiman et al. (2009) found that Bangladeshi households at the third and fourth income quintiles experienced more wasting than the poorest households in the case of food price increases. Furthermore, there has been some empirical evidence that by moving to cheaper foods and employing nonfood-based coping strategies, households may be able to maintain energy levels despite food price increases. For example, Jensen and Miller (2008) found no reduction in calories among poor households in China's Hunan province and a very small reduction in calories among poor households in Gansu province (indistinguishable from typical seasonal declines) when food prices increased in 2006. They also found evidence of consumers moving away from more expensive foods and a slight reduction in nonfood expenditure.

The strong pattern of the price effects on food consumption and calories stands in contrast to the standard result in the literature that poorer households have larger food price elasticities. ${ }^{36}$ The standard result hinges on the fact that richer households devote a much smaller share of their budgets to food and thus are not as affected by food price increases as poorer households. In Afghanistan, however, food (in particular, wheat) makes up a large portion of the budget for rich and poor households alike. Over $80 \%$ of the population spends more than half of their total budget on food. Those in the bottom quintile of the income distribution spend approximately $66 \%$ of their budget on food (44\% on wheat flour); even those in the top quintile spend approximately $49 \%$ of their budget on food $(20 \%$ on

\footnotetext{
${ }^{34}$ We note here the standard caution that the regression coefficients represent estimated effects from small, marginal price changes. This caution against using estimated marginal effects as a basis for simulating large, non-marginal price changes is particularly warranted in the case of quantile estimators where different estimated effects across the distribution of the dependent variable imply a changing shape of this distribution due to price changes. Variation in the estimated marginal effects at different points on the distribution can readily imply re-rankings of observations (in terms of the dependent variable) with large enough simulated changes. But this exercise would be nonsensical as one would expect that as the shape of the distribution changes, so too would each of the estimated marginal effects.

${ }^{35}$ For example, households in the top quintile of the calorie distribution spend nearly double on food away from home than households in the bottom quintile, and they provide more meals (approximately two per week) to guests.

${ }^{36}$ The elasticities are not completely comparable since we looked at calorie-price elasticities based on where the household lies on the calorie distribution, and in the literature the analyses often focus on demand for food based on a household's income quintile.
} 
Table 21.8 Effects of wheat flour price increases on food security across the distribution

\begin{tabular}{l|l|l|l|l|l}
\hline Quantiles & 10 th & 20 th & 30 th & 40 th & 50 th \\
\hline Real per capita monthly & $-0.131^{* *}$ & $-0.199^{* * *}$ & $-0.268^{* * *}$ & $-0.338^{* * *}$ & $-0.431^{* * *}$ \\
food consumption & {$[0.0521]$} & {$[0.0448]$} & {$[0.0440]$} & {$[0.0446]$} & {$[0.0475]$} \\
\hline Daily per capita calorie & -0.00531 & $-0.0724 * *$ & $-0.120^{* * *}$ & $-0.156^{* * *}$ & $-0.192^{* * *}$ \\
intake & {$[0.0439]$} & {$[0.0296]$} & {$[0.0277]$} & {$[0.0258]$} & {$[0.0268]$} \\
\hline Food consumption score & $-0.239^{* * *}$ & $-0.242^{* * *}$ & $-0.241^{* * *}$ & $-0.181 * * *$ & $-0.168^{* * *}$ \\
& {$[0.0575]$} & {$[0.0520]$} & {$[0.0479]$} & {$[0.0369]$} & {$[0.0302]$} \\
\hline Quantiles & 60 th & 70 th & 80 th & 90 th & OLS \\
\hline Real per capita monthly & $-0.505^{* * *}$ & $-0.590^{* * *}$ & $-0.706^{* * *}$ & $-0.721^{* * *}$ & $-0.423 * * *$ \\
food consumption & {$[0.0486]$} & {$[0.0546]$} & {$[0.0660]$} & {$[0.0759]$} & {$[0.036]$} \\
\hline Daily per capita calorie & $-0.225 * * *$ & $-0.266 * * *$ & $-0.313 * * *$ & $-0.377 * * *$ & $-0.187 * *$ \\
intake & {$[0.0287]$} & {$[0.0335]$} & {$[0.0372]$} & {$[0.0477]$} & {$[0.0243]$} \\
\hline Food consumption score & $-0.152^{* * *}$ & $-0.151^{* * *}$ & $-0.188^{* * *}$ & $-0.185 * * *$ & $-0.183 * *$ \\
& {$[0.0309]$} & {$[0.0300]$} & {$[0.0334]$} & {$[0.0329]$} & {$[0.0270]$} \\
\hline
\end{tabular}

Note: Coefficients and standard errors for the log of wheat flour prices are from separate, population-weighted regressions. The dependent variable is transformed using the inverse hyperbolic sine function and is listed in the first column. Control variables are listed in the text. Total observations: 20,483. UQR standard errors are clustered bootstrap estimates. OLS standard errors are corrected for clustering and stratification

$*, * *$, and $* * *$ denote significance at $10 \%, 5 \%$, and $1 \%$, respectively

wheat flour). Given the importance of food in the budget of Afghan households, it is plausible that even those households at the top of the distributions could have been affected significantly by the wheat flour price increases.

The estimates from the FCS regressions revealed that Afghan households had to make large concessions in dietary quality as a result of the food price increases (Table 21.8). In the case of Haiti, Brinkman et al. (2010) found similar declines in the FCS when rice prices increased. These findings indicated that households changed the composition of their diets, perhaps by cutting back on more expensive, nutrient-rich foods and moving toward cheaper foods. Since the UQR coefficients are related to a specific quantile of a specific distribution, we could not establish a link between the results for the three food-based coping responses. That is, households in a certain quantile on one distribution do not necessarily fall in the same quantile on another distribution; therefore, each set of coefficients must be interpreted separately. While we acknowledge that households may be giving up quality for quantity, we could not provide direct evidence using the UQR.

Our overall findings on food security are consistent with the literature on the impact of economic shocks on nutritional outcomes. For example, Klotz et al. (2008) argued that during times of economic crisis and when households cannot increase the amount that they spend on food, they are forced to cut back on expensive, micronutrient-rich foods to maintain their consumption of core staples. Therefore, economic shocks will lead to micronutrient deficiencies before weight loss. Jensen and Miller (2008) similarly found that in the face of food price inflation, poor urban 
households in China substitute more expensive foods with cheaper foods. Diagana et al. (1999) also found decreases in the level of dietary diversity and changes in food consumption patterns after the 1994 devaluation of the CFA franc using data from West Africa.

Our results also highlight the importance of moving beyond price effects on mean households when conducting policy analysis; in some instances, we observed stark differences between the coping responses of the average household and households at other points on the distributions. Figure 21.3a and b depict the UQR and OLS point estimates and the $95 \%$ confidence intervals for the food consumption and calorie regressions, respectively.

There are substantial differences between the UQR and OLS estimates for the food consumption and calorie regressions. OLS overestimated the responses of those at the lower portion of the distributions and underestimated the responses of those at the upper portion of the distributions. This could have policy implications.
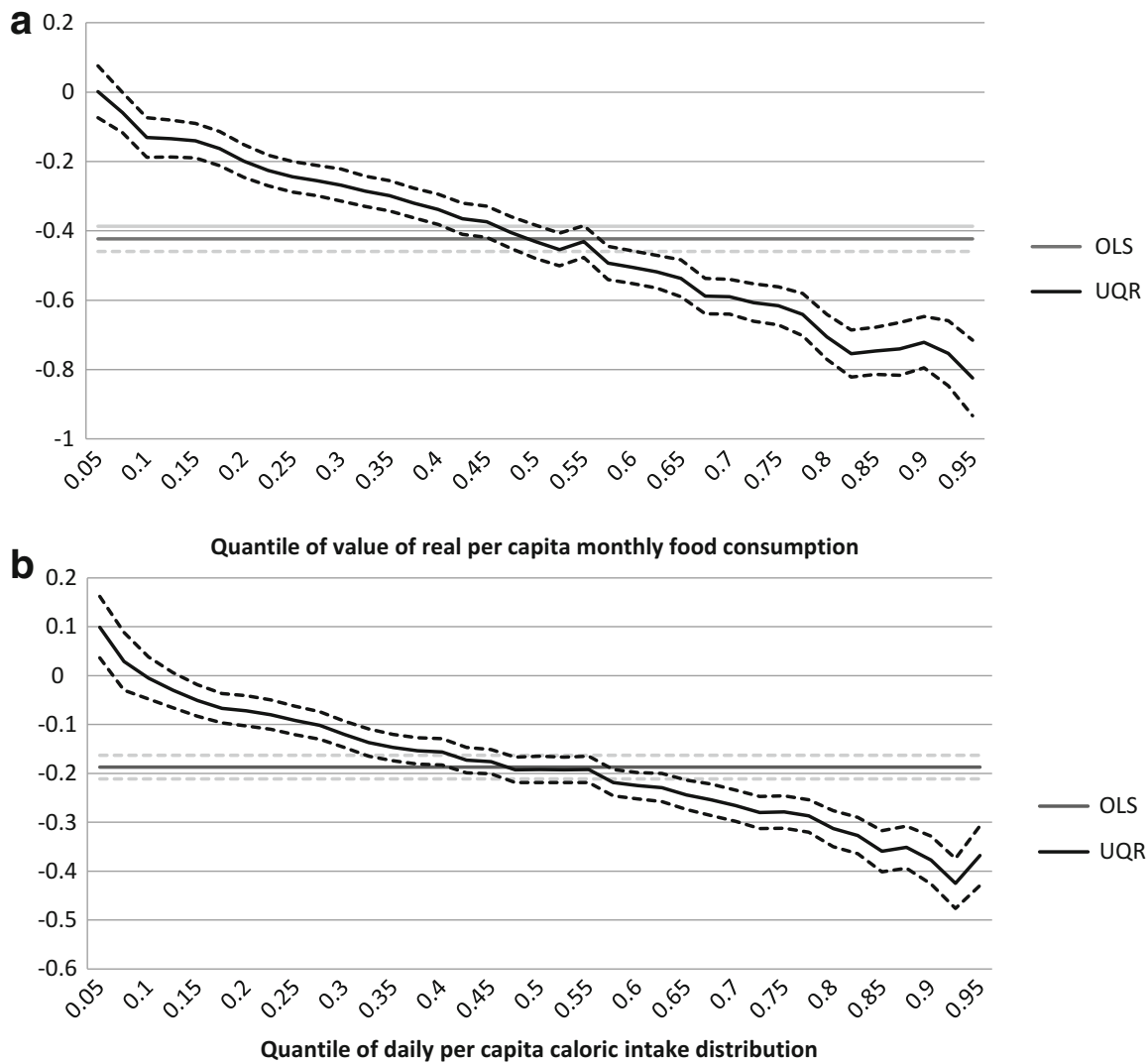

Fig. 21.3 (a) Food consumption-price effects (with $95 \%$ confidence intervals). (b) Calorie-price effects (with $95 \%$ confidence intervals) 
For example, if policymakers consider solely the OLS results for calories and then assume that all households, including the most vulnerable, reduce their caloric intake in response to the price increases, this could lead to blunt policy responses which focus on the provision of staple foods alone. These sorts of policies would not only exacerbate the price shock by shifting up the demand for staple food (through government purchases), but they are likely to be a relatively more expensive safety net option (given that price increase of the staple). More importantly, the UQR results showed that the most vulnerable households do not cut back on calories, and thus other policies may be more beneficial. It is likely that some of these households were forced to make other concessions, such as moving to lower quality and/or less nutritious foods; in this case, interventions like nutrient supplementation programs or the fortification of staple foods could address better the needs of those households.

\subsubsection{Supplemental Results}

To explore further the impact of the price increases on food security, we looked at several supplemental indicators of diet quality to examine the potential nutritional consequences of dietary changes. We examined three essential micronutrients (retinol, beta-carotene, iron) and the three macronutrients (protein, carbohydrates, fat). Retinol and beta-carotene are forms of vitamin A, an important nutrient for vision and immune system functions. Iron is critical for growth and development, immune system functions, and overall metabolism. Both vitamin A and iron deficiencies are ubiquitous in developing countries and have been recognized as major public health challenges (Dufour and Borrel 2007; Fanzo and Pronyk 2010; Ramakrishnan 2002). The three macronutrients provide energy (or calories) to the body and are essential — in large quantities_-for survival. Similar to the food-based coping response regressions above, we used the inverse hyperbolic sine function to transform these dependent variables and used the UQR estimator to estimate the price effects based on a household's position on the unconditional distribution of the respective nutrient intake variable.

We observed declines in nutrient intakes as a result of the wheat flour price increases (Table 21.9). The results differed by the type of nutrient as well as the position of a household on the distribution of nutrient intake. We found declines in the intake of iron, retinol, and beta-carotene for most households, with the lowest deciles of the distributions being an exception (and for beta-carotene, those in the top deciles as well). The general declines are consistent with the findings of Ecker and Qaim (2011), who found negative staple food price elasticities (at population means) for iron and vitamin A (and protein) in Malawi.

In terms of macronutrients, we found a decline in the intake of protein, fat, and carbohydrates; the intake of the first two macronutrients showed larger declines, as may have been expected since protein and fat are more expensive sources of calories than carbohydrates. We found that households at the lower end (e.g., first and second deciles) of these distributions did not experience statistically significant declines. 


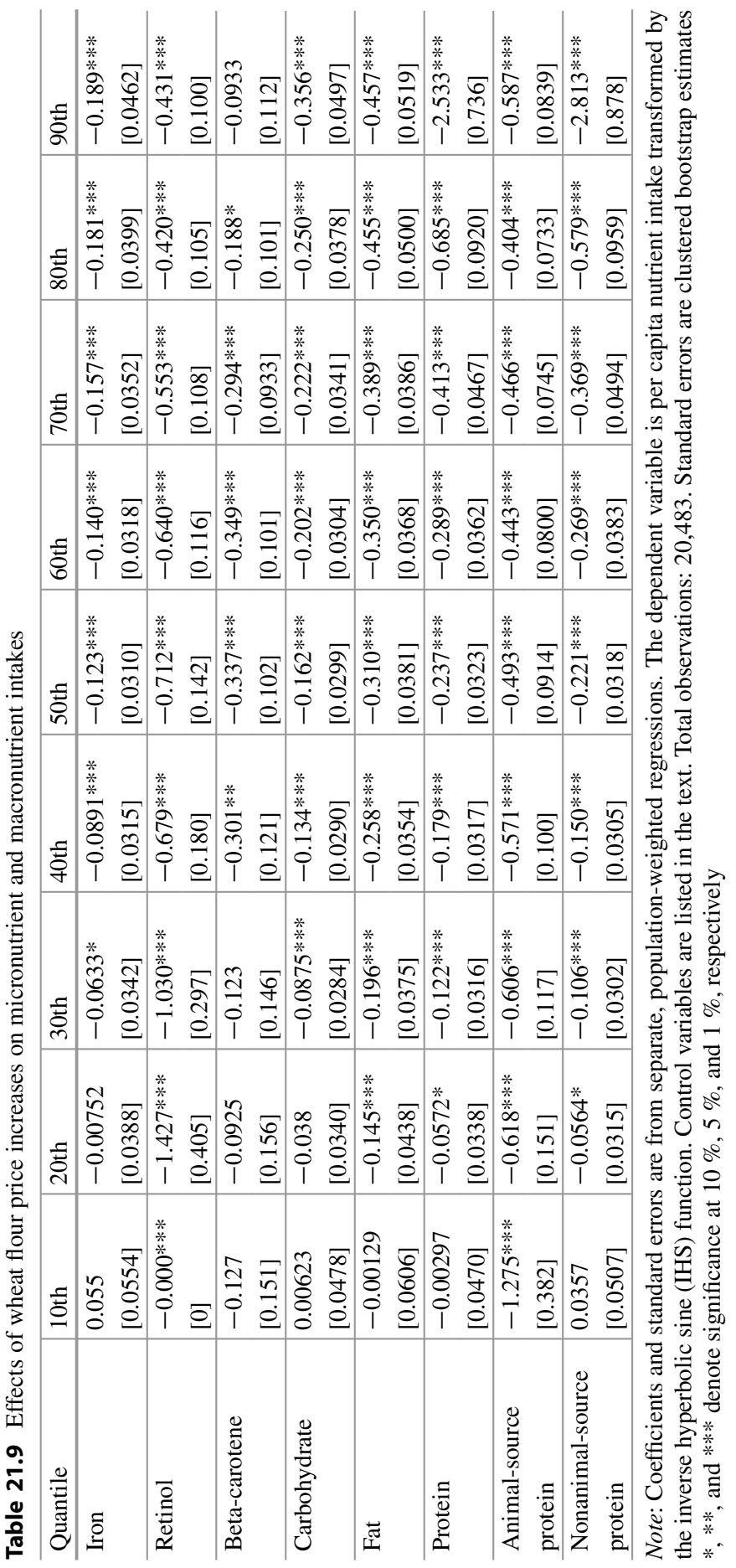


We further separated protein-based food into two categories: animal-source foods and nonanimal-source foods. Higher animal-source and nongrain food expenditures have been linked to lower levels of malnutrition as measured by child stunting (Sari et al. 2010). We found that the expenditure on animal-source protein declined much more than nonanimal-source protein when food prices increase; the former is a more expensive source of calories than the latter. The largest change overall was the decline in protein from animal sources for those consuming at the lowest decile. Across each of the deciles, the negative elasticity of protein from animal sources was the largest change of the macronutrients. These findings are consistent with the fact that as purchasing power declines, households move away from more expensive and often nutritious calories, such as meat, to cheaper less nutritious ones, such as pulses and beans. The findings are also consistent with previous literature on economic shocks. Martin-Prevel et al. (2000) and Block et al. (2004) found reductions in maternal and child nutritional status following a currency devaluation and a financial crisis.

\subsection{Conclusion}

Unique household and price data collected before and during the 2007/2008 food price crisis provided a rare opportunity to examine empirically nonfood-based and food-based coping strategies used by households in Afghanistan in response to sharp increases in the price of wheat flour, their dietary staple. In a country where decades of conflict, political instability, and recurring drought have led to a precarious state of food insecurity and poverty, understanding how households cope with price increases and other economic shocks can provide vital information to policymakers and aid organizations tasked with creating and implementing programs and policies to address acute and chronic food insecurity and poverty in Afghanistan.

In response to wheat flour price increases, we found that Afghan households reduced food expenditure and also expenditure on health, grooming, communication, transportation, cigarettes and tobacco, and culture. The reductions in health expenditures are of particular concern, especially in a country that ranks at the bottom of many development, health, and nutritional rankings. Such coping responses could have long-term consequences if they represent reductions in important medical care or health investments.

We did not find changes in educational expenses, school enrollment, or child clothing, which can be categorized as child goods. The reductions in expenditures on grooming, adult clothing, and cigarettes and tobacco suggest Afghan households were more willing to reduce spending on adult goods than child goods. While we did not observe any increase in the sale of productive assets (livestock) or in migration, we did find an increase in the frequency at which households used credit to purchase food.

The food price increases also led Afghan households to employ several foodbased coping strategies. Households reduced the real per capita monthly value of food consumed and as a result experienced reductions in daily per capita caloric 
intake and household dietary diversity. Rather than reducing calories by the same amount as the reductions in the value of food consumed, households adjusted the types of foods they ate; most likely, they switched to lower quality, cheaper foods, or food groups.

We further analyzed the food-based coping responses by examining the differences in the behavioral response of a household based on its location on the distribution of the respective food-based coping response indicators. Those wishing to target policies and programs at vulnerable, food-insecure households may be interested in knowing the unique set of trade-offs that these households face. Households at the bottom of the caloric intake distribution made very small to no reductions in caloric intake. Households living near caloric-subsistence levels are vulnerable to many adverse health effects and need to find ways to absorb the price shock without further reducing calories. These vulnerable households may have limited options in buffering food price shocks; while we know that food purchases make up the vast majority of their total consumption, they cannot easily scale back on calories. Whereas we found that households at the top of the distribution did experience significant declines in caloric intake. Similarly, households at the top of the food consumption distribution experienced larger declines than those at the bottom of the distribution, though unlike in the calorie regressions, even those at bottom experienced significant declines. Such differences in behavioral responses show that a quantile estimator (or any estimator that allows marginal effects to vary across the distribution) can reveal important information, particularly when examining welfare-related outcomes.

We also found evidence of declines in dietary diversity across the entire distribution of households in Afghanistan, underscoring the vulnerability of Afghan households to food price increases. Long-run policy solutions recognize that vulnerable households are likely to be disproportionately hurt by negative shocks. Antipoverty programs aimed at increasing the income of the poor and improving access to infrastructure and education could better protect people from price shocks by providing them with better coping strategies (e.g., drawing down savings rather than decreasing health expenditure).

A long-run approach alone can, however, leave the population vulnerable to shocks in the short and medium run. Short-run interventions can play a potentially important role in protecting the population from long-run adverse effects of food price shocks. As an example, our analysis demonstrated that dietary quality (dietary diversity, as well as nutrient intake) declined significantly during a period of high food prices. Examples of interventions that focus on diet quality include micronutrient supplementation programs (such as "sprinkles"), expansion of the fortified school biscuit program, wheat flour fortification (e.g., with iron, folic acid, or vitamin A), and biofortification of staple crops. Such interventions play a relatively small role in food assistance programs. For example, between 2005 and 2009, more than 1.12 million metric tons of food aid was delivered to Afghanistan to provide emergency food relief and nutritional support to vulnerable and acutely food-insecure households; more than three-fourths of this aid was comprised of wheat products. It is important to note that our findings do not argue against the 
provision of calories through the release of staple crop reserves. Even though we found that those whose calorie consumption is at the margin of basic caloric needs are not reducing their caloric intake during an adverse price shock, this does not mean that the provision of some form of calories will not be of help to them. The receipt of a staple crop could very well be a useful transfer, allowing the household to supplement the staple crop with a more diverse diet or purchase necessary nonfood items. The standard response to food crises-increasing the distribution of grains-is useful because it essentially increases the ability of a household to consume a more diverse diet. The key findings in this analysis, though, put more emphasis on the importance of enhancing the current standard policy response with interventions aimed directly at addressing dietary diversity through micronutrient interventions, such as fortification of grains or nutrient supplementation.

Another policy implication related to the monitoring of a population's vulnerability to food insecurity. In their guidelines for assessing household-level food security, the Food and Agriculture Organization of the United Nations and the World Food Programme (2009) suggested the construction of a food consumption score, food expenditure estimates, and caloric intake. The guidelines have been written to provide assistance to on-the-ground teams which assess whether action needs to be taken to address the potential problems of food insecurity. The guidelines are intended to be practical responses to data-poor environments and suggest that information on any of these indicators could be informative, but our findings are less optimistic about the informativeness of calories as a proxy for food security in the short run. Our findings indicated that calories are relatively insensitive (at least in the short run) to adverse shocks, while dietary diversity is more sensitive to shocks. This is consistent with the findings of Ruel (2003), who found that dietary changes can be detected before changes in micronutrient status. The key point is that policies designed to be triggered by a decline in caloric intake to below the subsistence level will fail to detect the onset of food insecurity in a timely way.

Finally our findings shed some light on the costs and benefits of collecting data on diversity and calories. Household survey consumption modules often include questions about the quantity of food consumed and food expenditure, but questions about the frequency of food consumption are seldom asked. Given its low cost, it may be beneficial to consider augmenting household surveys by adding such questions, particularly for populations that are vulnerable to food insecurity. Measures of dietary diversity are a useful tool when detailed food journals or anthropometric data are not available. A common view is that there is a trade-off between different measures, such as the food consumption score and calorie measures. Calorie data is time consuming to collect, but it is presumably a better indicator of food security, while dietary diversity data is easier to collect, but it is a cruder, less informative measure. Alexander and Thomson (1992) discussed the importance of collecting frequency data in addition to quantity intake data. They demonstrated that both the quantity and frequency of food intake are important determinants of diet-induced diseases, and they argued that looking solely at quantity data could be misleading. Our findings suggest that using dietary diversity indicators may be the best approach to measuring 
the onset of food insecurity. This view is supported by recent literature comparing various measures of food security (Headey and Ecker 2013; Tiwari et al. 2013).

Acknowledgments The authors are grateful to the Central Statistics Organization, Government of Afghanistan (GoA), for granting access to the data for poverty research. Findings from this analysis provided background information for the World Bank's poverty assessment for Afghanistan and have informed the GoA Ministry of Economy. The authors wish to thank for comments of Ismail Rahimi and participants at the ZEF-IFPRI Workshop on Food Price Volatility and Food Security. D'Souza is an Associate Professor at the School of Public Affairs, Baruch College, CUNY; Jolliffe is a Senior Economist at the World Bank and also holds affiliations with the Institute for the Study of Labor (IZA) in Bonn and with the National Poverty Center (NPC) at the Ford School of Public Policy, University of Michigan. The views expressed here are those of the authors and may not be attributed to the World Bank, IZA, or NPC.

\section{Appendix}

Table 21.10 Key indicators across quarters

\begin{tabular}{l|r|r|r|r|r}
\hline & $\begin{array}{l}\text { Quarter 1 } \\
\text { (fall) }\end{array}$ & $\begin{array}{l}\text { Quarter 2 } \\
\text { (winter) }\end{array}$ & $\begin{array}{l}\text { Quarter 3 } \\
\text { (spring) }\end{array}$ & $\begin{array}{l}\text { Quarter 4 } \\
\text { (summer) }\end{array}$ & All \\
\hline \begin{tabular}{l} 
Demographic Indicators \\
\hline Average household size*
\end{tabular} & 8.7 & 9.0 & 8.4 & 8.5 & 8.6 \\
\hline Average age (years) & 20.6 & 20.4 & 20.7 & 20.5 & 20.6 \\
\hline Household members \%, age <15) & 47.9 & 48.7 & 48.4 & 48.7 & 48.5 \\
\hline Age dependency ratio & 131.6 & 134.2 & 133.6 & 134.0 & 133.4 \\
\hline Education and health indictors & 33.0 & 41.1 & 34.8 & 37.6 & 36.7 \\
\hline $\begin{array}{l}\text { Full Immunization (\%, age 12-23 } \\
\text { months)* }\end{array}$ & 34.4 & 28.8 & 28.4 & 29.5 & 30.1 \\
\hline Literate household head (\%)* & 21.7 & 21.3 & 18.9 & 21.6 & 20.9 \\
\hline \begin{tabular}{l} 
Ever attended school (\%, age $>18) *$ \\
\hline Education level of persons (age $>18)$
\end{tabular} & 2.0 & 1.9 & 1.6 & 1.9 & 1.9 \\
\hline $\begin{array}{l}\text { Access to services and infrastructure } \\
\text { indicators }\end{array}$ & 5.9 & 5.6 & 4.5 & 4.0 & 4.9 \\
\hline Sanitary toilet (\% households) & 40.9 & 42.2 & 41.5 & 39.8 & 41.1 \\
\hline Electricity (\% households)
\end{tabular}

Source: NRVA 2007/2008. Note: Population-weighted means

* denotes estimates that are statistically different at $10 \%$ across quarters in some cases 
Open Access This chapter is distributed under the terms of the Creative Commons AttributionNoncommercial 2.5 License (http://creativecommons.org/licenses/by-nc/2.5/) which permits any noncommercial use, distribution, and reproduction in any medium, provided the original author(s) and source are credited.

The images or other third party material in this chapter are included in the work's Creative Commons license, unless indicated otherwise in the credit line; if such material is not included in the work's Creative Commons license and the respective action is not permitted by statutory regulation, users will need to obtain permission from the license holder to duplicate, adapt or reproduce the material.

\section{References}

Alexander CJ, Thomson FJ (1992) The threshold effect: consequences of change in the frequency of food intake in the presence of a functional threshold. Med Hypotheses 39(3):302-308. doi:10. 1016/0306-9877(92)90128-y

Anríquez G, Daidone S, Mane E (2013) Rising food prices and undernourishment: a cross-country inquiry. Food Policy 38:190-202. doi:10.1016/j.foodpol.2012.02.010

Arimond M, Ruel MT (2004) Dietary diversity is associated with child nutritional status: evidence from 11 demographic and health surveys. J Nutr 134(10):2579-2585

Balagtas JV, Bhandari H, Mohanty S, Cabrera E, Hossain M (2012) Impact of a commodity price spike on poverty dynamics: evidence from a panel of rural households in Bangladesh. Paper presented at the Australian Agricultural and Resource Economics Society, Fremantle

Bibi S, Cockburn J, Coulibaly M, Tiberti L (2009) The impact of the increase in food prices on child poverty and the policy response in Mali. Working paper 2009 - 02. UNICEF Innocenti Research Centre

Block SA, Kiess L, Webb P, Kosen S, Moench-Pfanner R, Bloem MW, Peter Timmer C (2004) Macro shocks and micro outcomes: child nutrition during Indonesia's crisis. Econ Hum Biol 2(1):21-44. doi:10.1016/j.ehb.2003.12.007

Brinkman H-J, de Pee S, Sanogo I, Subran L, Bloem MW (2010) High food prices and the global financial crisis have reduced access to nutritious food and worsened nutritional status and health. J Nutr 140(1):153S-161S. doi:10.3945/jn.109.110767

Buchinsky M (1994) Changes in the U.S. wage structure 1963-1987: application of quantile regression. Econometrica 62(2):405-458

Burbidge JB, Magee L, Robb AL (1988) Alternative transformations to handle extreme values of the dependent variable. J Am Stat Assoc 83(401):123-127

Buse RC, Salathe LE (1978) Adult equivalent scales: an alternative approach. Am J Agric Econ 60(3):460-468

Carter MR, Lybbert TJ (2012) Consumption versus asset smoothing: testing the implications of poverty trap theory in Burkina Faso. J Dev Econ 99(2):255-264. doi:10.1016/j.jdeveco.2012. 02.003

Chabot P, Dorosh PA (2007) Wheat markets, food aid and food security in Afghanistan. Food Policy 32(3):334-353. doi:10.1016/j.foodpol.2006.07.002

Chamberlain G (1994) Quantile regression, censoring, and the structure of wages. In: Christopher $\mathrm{S}$ (ed) Advances in econometrics. Elsevier, New York

Compton J, Wiggins S, Keats S (2010) Impact of the global food crisis on the poor: what is the evidence? Overseas Development Institute, London

Deaton A, Kozel V (2005) Data and dogma: the great Indian poverty debate. World Bank Res Obs 20(2):177-199. doi:10.1093/wbro/lki009

Deaton A, Paxson C (1998) Economies of scale, household size, and the demand for food. J Polit Econ 106(5):897-930

de Hoyos RE, Medvedev D (2011) Poverty effects of higher food prices: a global perspective. Rev Dev Econ 15(3):387-402. doi:10.1111/j.1467-9361.2011.00615.x 
Diagana B, Akindès F, Savadogo K, Reardon T, Staatz J (1999) Effects of the CFA franc devaluation on urban food consumption in West Africa: overview and cross-country comparisons. Food Policy 24(5):465-478. doi:10.1016/s0306-9192(99)00060-3

D'Souza A, Jolliffe D (2013) Conflict, food price shocks, and food insecurity: the experience of Afghan households. Food Policy 42:32-47. doi:10.1016/j.foodpol.2013.06.007

D'Souza A, Jolliffe D (2014) Food insecurity in vulnerable populations: coping with food price shocks in Afghanistan. Am J Agric Econ 96(3):790-812. doi:10.1093/ajae/aat089

Dufour C, Borrel A (2007) Towards a public nutrition response in Afghanistan: evolutions in nutritional assessment and response. In: Pain A, Sutton J (eds) Reconstructing agriculture in Afghanistan. FAO and Practical Action, Warwickshire

Ecker O, Qaim M (2011) Analyzing nutritional impacts of policies: an empirical study for Malawi. World Dev 39(3):412-428. doi:10.1016/j.worlddev.2010.08.002

Fanzo J, Pronyk P (2010) An evaluation of progress toward the Millennium Development Goal One Hunger target: a country-level, food and nutrition security perspective. World Food Programme, Rome

FAO (2008) The state of food security in the world. FAO, Rome

FAO (2011) Global food losses and food waste. Food and Agriculture Organization, United Nations, Rome

FAO (2012) FAOSTAT

FAO GIEWS (2014) Food price data. Food and Agriculture Organization of the United Nations (FAO) and Global Information and Early Warning System (GIEWS)

FAO, World Food Programme (2009) FAO/WFP joint guidelines for crop and food security assessment missions (CFSAMs). FAO and WFP, Rome

Firpo S, Fortin N, Lemieux T (2009a) Supplement to "unconditional quantile regressions": estimation and testing. Econometrica 77(3):953-973

Firpo S, Fortin N, Lemieux T (2009b) Unconditional quantile regression. Econometrica 77(3):953973

Foreign Agricultural Service, USDA (2008) Afghanistan: severe drought causes major decline in 2008/09 wheat production. Commodity Intelligence Report. Kabul

Friedman J, Hong SY, Hou X (2011) The impact of the food price crisis on consumption and caloric availability in Pakistan: evidence from repeated cross-sectional and panel data. HNP discussion paper. World Bank, Washington, DC

Giustozzi A, Ibrahimi N (2012) Thirty years of conflict: drivers of anti-government mobilisation in Afghanistan, 1978-2011. Afghanistan Research and Evaluation Unit Issues Paper

Green C, Kirkpatrick CH (1982) A cross-section analysis of food insecurity in developing countries: its magnitudes and sources. J Dev Stud 18(2):181-200

Guarcello L, Mealli F, Rosati F (2010) Household vulnerability and child labor: the effect of shocks, credit rationing, and insurance. J Popul Econ 23(1):169-198. doi:10.1007/s00148-0080233-4

Hadley C, Stevenson EGJ, Tadesse Y, Belachew T (2012) Rapidly rising food prices and the experience of food insecurity in urban Ethiopia: impacts on health and well-being. Soc Sci Med 75(12):2412-2419. doi:10.1016/j.socscimed.2012.09.018

Hampel F, Ronchetti E, Rousseeuw P, Stahel W (1988) Robust statistics: the approach based on influence functions. Wiley, New York

Headey D, Ecker O (2013) Rethinking the measurement of food security: from first principles to best practice. Food Secur 5(3):327-343. doi:10.1007/s12571-013-0253-0

Holleman C, Moloney G (2009) Somalia's growing urban food security crisis. Humanitarian Exchange 42:12-16

IMF (2009) International Financial Statistics Database. International Monetary Fund, Washington, DC

International Fund for Agricultural Development (2008) Soaring food prices and the rural poor: feedback from the field. IFAD, Rome. Available at http://www.ifad.org/operations/food/food. $\mathrm{htm}$ 
Islamic Republic of Afghanistan, M. o. E., and the World Bank Economic Policy and Poverty Sector (2010) Poverty status in Afghanistan: a profile based on the national risk and vulnerability assessment (NRVA) 2007/08. Islamic Republic of Afghanistan, Ministry of Economy, and the World Bank Economic Policy and Poverty Sector, Kabul

Islamic Republic of Afghanistan, Central Statistics Organization (CSO), \& World Bank Economic Policy and Poverty Sector (2011) Setting the official poverty line for Afghanistan. Kabul. Available at http://www.cso.gov.af/en/documents?DID $=210$

Ivanic M, Martin W (2008) Implications of higher global food prices for poverty in low-income countries. SSRN eLibrary

Jacobs PT (2010) Household food insecurity, rapid food price inflation and the economic downturn. Paper presented at the Agricultural Economists Association of South Africa annual conference, Cape Town

Jensen RT, Miller NH (2008) The impact of food price increases on caloric intake in China. Agric Econ 39:465-476. doi:10.1111/j.1574-0862.2008.00352.x

Johnecheck W, Holland DE (2007) Nutritional status in postconflict Afghanistan: Evidence from the National Surveillance System Pilot and National Risk and Vulnerability Assessment. Food Nutr Bull 28(1):3-17

Johnson NL (1949) Systems of frequency curves generated by methods of translation. Biometrika 36(1/2):149-176

Kish L (1965) Survey sampling. Wiley, New York

Klotz C, de Pee S, Thorne-Lyman A, Kraemer K, Bloem MW (2008) Nutrition in the perfect storm: why micronutrient malnutrition will be a widespread health consequence of high food prices. Sight Life Mag 2:6-13

Koenker R, Bassett G Jr (1978) Regression quantiles. Econometrica 46(1):33-50

Koenker R, Bassett G Jr (1982) Robust tests for heteroscedasticity based on regression quantiles. Econometrica 50(1):43-61

Lautze S, Stites E, Nojumi N, Najimi F (2002) Qaht-e-pool "a cash famine”: food insecurity in Afghanistan 1999-2002: Feinstein International Center, Tufts University

Layton DF (2001) Alternative approaches for modeling concave willingness to pay functions in conjoint valuation. Am J Agric Econ 83(5):1314-1320

MacKinnon JG, Magee L (1990) Transforming the dependent variable in regression models. Int Econ Rev 31(2):315-339. doi:10.2307/2526842

Maletta H (2004) Winters of discontent: seasonal changes in wages and food prices in Afghanistan, 2002-2003. FAO discussion paper

Martin-Prevel Y, Delpeuch F, Traissac P, Massamba J-P, Adoua-Oyila G, Coudert K, Treche S (2000) Deterioration in the nutritional status of young children and their mothers in Brazzaville, Congo, following the 1994 devaluation of the CFA franc. Bull World Health Organ 78:108-118

Micronutrient Initiative \& UNICEF (2009) Investing in the future: a united call to action on vitamin and mineral deficiencies. Micronutrient Initiative, Ontario

Minot N, Dewina R (2013) Impact of food price changes on household welfare in Ghana. IFPRI discussion paper 01245

National Planning Commission \& Central Bureau of Statistics (2013) Nepal thematic report on food security and nutrition: Government of Nepal

Persaud S (2010) Price volatility in Afghanistan's wheat market. E-Outlook Report: U.S. Department of Agriculture, Economic Research Service

Ramakrishnan U (2002) Prevalence of micronutrient malnutrition worldwide. Nutr Rev 60:S46S52. doi:10.1301/00296640260130731

Robles M, Torero M (2010) Understanding the impact of high food prices in Latin America. Economía 10(2):117-164

Ruel MT (2003) Operationalizing dietary diversity: a review of measurement issues and research priorities. J Nutr 133(11):3911S-3926S

Ruel MT, Garrett JL, Hawkes C, Cohen MJ (2010) The food, fuel, and financial crises affect the urban and rural poor disproportionately: a review of the evidence. J Nutr 140(1):170S-176S. doi:10.3945/jn.109.110791 
Sanogo I (2009) The global food price crisis and household hunger: a review of recent food security assessments. Humanitarian Exchange 42:8-11

Sari M, de Pee S, Bloem MW, Sun K, Thorne-Lyman AL, Moench-Pfanner R, Akhter N, Kraemer K, Semba RD (2010) Higher household expenditure on animal-source and nongrain foods lowers the risk of stunting among children 0-59 months old in Indonesia: implications of rising food prices. J Nutr 140(1):195S-200S. doi:10.3945/jn.109.110858

Simler KR (2010) The short-term impact of higher food prices on poverty in Uganda. SSRN eLibrary

Steyn NP, Nel JH, Nantel G, Kennedy G, Labadarios D (2006) Food variety and dietary diversity scores in children: are they good indicators of dietary adequacy? Public Health Nutr 9(5):644650

Sulaiman M, Parveen M, Das NC (2009) Impact of the food price hike on nutritional status of women and children. Research monograph series no. 38. BRAC Research and Evaluation Division, Dhaka

Tandon S, Landes M (2014) Coping strategies in response to rising food prices: evidence from India. Economic research service. Economic research report number 177. November

Tiwari S, Zaman H (2010) The impact of economic shocks on global undernourishment. World Bank policy research working paper series 5215

Tiwari S, Skoufias E, Sherpa M (2013) Shorter, cheaper, quicker, better: linking measures of household food security to nutritional outcomes in Bangladesh, Nepal, Pakistan, Uganda and Tanzania. World Bank policy research working paper WPS6584. World Bank, Washington, DC

Torlesse H, Kiess L, Bloem MW (2003) Association of household rice expenditure with child nutritional status indicates a role for macroeconomic food policy in combating malnutrition. $\mathrm{J}$ Nutr 133:1320-1325

Ul Haq Z, Nazli H, Meilke K (2008) Implications of high food prices for poverty in Pakistan. Agric Econ 39:477-484. doi:10.1111/j.1574-0862.2008.00353.x

UNICEF (2009) Tracking progress on child and maternal nutrition: a survival and development priority

United Nations Development Program (2009) Human development report 2009

UNODC (2008) Violent incidents data. United Nations Office on Drugs and Crimes, Kabul

Weismann D, Bassett L, Benson T, Hoddinott J (2009) Validation of the World Food Programme's food consumption score and alternative indicators of household food security. Discussion paper. IFPRI

Wodon QT, Tsimpo C, Backiny-Yetna P, Joseph G, Adoho F, Coulombe H (2008) Potential impact of higher food prices on poverty: summary estimates for a dozen west and central African countries. The World Bank policy research working paper series, 4745

World Bank \& International Monetary Fund (2012) Global monitoring report 2012: food prices, nutrition and the millennium development goals. Washington, DC 